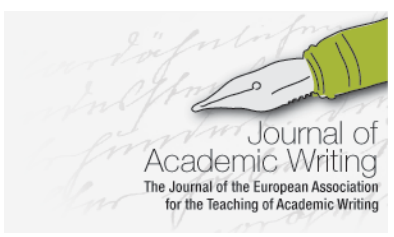

Journal of Academic Writing

Vol. 11 No 1 Summer 2021, pages 16-44 https://doi.org/10.18552/joaw.v11i1.632

\title{
Using Author-devised Cover Letters Instead of Instructor-devised Rubrics to Generate Useful Written Peer Feedback Comments
}

\author{
Roger M. A. Yallop \\ University of Tartu \\ Djuddah A. J. Leijen \\ University of Tartu
}

\begin{abstract}
This study uses both qualitative and quantitative research methods in a mixed-methods approach to investigate whether the principled use of author-devised cover letters (CLs) within doctorate writing groups can result in more useful reviewer feedback comments than would be attained through the use of instructor-devised writing assessment rubrics. In this context, CLs are self-devised written documents that help the reviewers give the author useful and critical written feedback comments. Twenty participants in different discipline-specific writing groups were given explicit instruction about the importance and content of CLs during the peer feedback process. Their perceptions of a useful CL were obtained from post-course questionnaires and analysed qualitatively. In addition, their CLs at various stages of the feedback process were analysed quantitatively for genre, social presence, and evidence of teaching instruction, and compared to the CLs produced by $20 \mathrm{PhD}$ students in similar writing groups who received minimal CL instruction. The study found that author-devised CLs, as opposed to instructor-devised rubrics, can allow the authors the flexibility of providing textspecific background details, requesting reviewer help on specific textual aspects, using social presence to develop a sense of writing community, and provide reflection upon their own writing.
\end{abstract}

\section{Introduction}

There is much evidence that academic writing groups are an effective method to support PhD students' writing skills (Aitchison, 2009; Murray \& Moore, 2006; Rollinson, 2004). As one part of the process, $\mathrm{PhD}$ students periodically submit to their group members (i.e. their peers) a section of their draft for review. Then, the group members give and receive written feedback on each other's submitted drafts. Finally, the authors have to decide whether to implement, or not to implement, the given feedback in order to improve their subsequent drafts. Many instructors use online peer feedback systems such as Peerceptiv (Gao, Schunn, \& Yu, 2019) and MyReviewers (Leijen \& Leontjeva, 2012) to facilitate this process. Within these systems, the instructors can select a suitable writing assessment rubric (rubric) as the criterion for giving feedback. Thus, the reviewers give their asynchronous written feedback comments based upon the author's draft and the selected rubric. However, instructor-devised rubrics may restrict the authors in communicating their specific feedback needs to their reviewers. Rubrics do not allow the authors the flexibility of providing text-specific background details, requesting reviewer help on specific textual aspects, and using affect to develop a sense of writing community that promotes deeper learning (e.g. Garrison, Cleveland-Innes \& Fung, 2010). One way to circumnavigate these restrictions is to allow the authors to devise their own self-assessment 
criteria by way of a cover letter (CL). CLs ${ }^{1}$, in this context, are the means by which authors can communicate to their reviewers about how their drafts should be assessed. CLs often contain affective language, textual background information, and requests for reviewer help (see Table 1).

Table 1. Example of participant $\mathrm{CL}^{2}$

\author{
Hello! \\ First of all, thank you for reading my draft, I really appreciate it! \\ What I am submitting is an introduction to the upcoming article, which will be an overview of means \\ of conveying commands. My target article is ... and the intended readers are teachers and \\ educational scientists. I will appreciate short, concise and as specific comments as possible (no sugar- \\ coating needed) about the following: \\ - Is the structure clear and understandable? \\ - Is the last part about connecting evidentiality with commands in an appropriate place ...?
}

If you have any suggestions of how I could become more articulate/express myself better, they are more than welcome, and any other feedback you might have $(-)$.

This draft is a bit of a mess, but I hope it is understandable, and thank you once more!

I look forward to your comments.

All the best, Participant

Feedback studies have shown that useful written feedback comments can have both a positive affect and/or a positive effect on the author's revision process. Affective comments (e.g. "Well done!") can increase author engagement (Cho, Schunn \& Charney, 2006; Nelson \& Schunn 2009 ) in the feedback process that can lead to more textual revisions (Gee, 1972). Affect in feedback comments can also help to develop a sense of writing community that promotes critical thinking (e.g. Garrison, Cleveland-Innes \& Fung, 2010) and reflective practices (e.g. Cahusac de Caux et al., 2017; Lam et al., 2019). Regarding effect, there is consensus in the literature that at higher levels of study useful feedback comments are text-specific (e.g. Ferris, 1997), justified (e.g. Leijen, 2017), global (e.g. Liu \& Sadler, 2003), and contain hedging devices (Hyland \& Hyland, 2000). CLs can help reviewers write useful feedback comments that also meet the author's feedback expectations (Yallop, Taremaa, \& Leijen, in press). Thus, a useful $C L$ should help reviewers write useful feedback comments, and useful feedback comments are likely to exert a positive affect and/or a positive effect on the author's revision process. However, and apart from studies conducted by the authors (Yallop, 2016; Yallop, 2017; Yallop \& Leijen, 2018; Yallop, Taremaa \& Leijen, in press), there seems to be little research into how CLs can be used to generate useful written feedback comments in tandem with, or instead of, rubrics within the peer feedback process within any educational context.

The process of giving feedback comments can also help reviewers become better writers. Nicol, Thomson and Breslin (2013, p. 111) found that approximately two-thirds of their participants (undergraduate engineering students) perceived reviewing as a way of "reflecting back on their own work and/or in their transferring ideas generated through the reviewing process to inform that work." In other words, the process of giving feedback can also promote reflection on the reviewer's own writing process. This claim is further supported by Lundstrom and Baker's (2009) study of L2 English university students where they found that their participants' writing skills improved more in their feedback role as a reviewer than as a feedback recipient. These two studies indicate that giving feedback at any level of study can help promote reflective writing practices. Similarly, the process of writing CLs could also help authors to reflect upon their writing.

\footnotetext{
${ }^{1}$ In this study, the authors use the term cover letter as explained by Mikkelsen (2010, p. 18) to refer loosely to an author-devised writing assessment rubric. The term cover letter does not relate to a written document in which the author explains how s/he has responded to her/his reviewers' feedback comments as used in other studies (e.g. Daniel, Gaze \& Braasch, 2014) or in resubmitted articles for peer review.

${ }^{2}$ All examples reproduced verbatim, and with participants' informed consent.
} 
Consequently, this study investigates what may constitute a useful $C L$ within the peer feedback context by examining 120 CLs produced by forty L2 English PhD students in different disciplinespecific writing groups. Twenty $\mathrm{PhD}$ students in doctorate writing groups were given explicit teaching instruction about the importance and content of CLs during the peer feedback process over a three-month period. At the end of the course, the same PhD students were asked about their perceptions of a good CL through a questionnaire and this data was analysed qualitatively in a grounded theory tradition (Strauss \& Corbin, 1997). In a separate line of research, the participants' CLs at different stages of the feedback process were analysed for content and compared to the CLs produced by 20 matched counterparts in similar writing groups who had been given minimal $C L$ instruction. The content of the CLs was analysed quantitatively using coding books derived from the data using thematic analysis (Braun \& Clarke, 2006). Affective language used by the participants in their CLs was measured using an amended version of a taxonomy to measure affect within reviewer written feedback comments (Yallop, 2016, p. 295). Quantitative indicators (e.g. the number of explicit references to teaching material) were used to measure the influence of teaching instruction on the content of CLs between the $20 \mathrm{PhD}$ students who received minimal CL instruction and the $20 \mathrm{PhD}$ students who received extensive $\mathrm{CL}$ instruction. The paper concludes by suggesting the structure and composition of what may constitute a useful CL. Thus, the purpose of this study is to determine whether the principled use of author-devised CLs within doctorate writing groups can result in more effective reviewer feedback comments than would be attained through the use of instructor-devised rubrics.

\section{Theoretical background}

\section{Writing assessment rubrics versus CLs}

It is common practice for students to give written feedback comments based upon a rubric (Cho, Schunn \& Wilson, 2006; Lundstrom \& Baker, 2009). These rubrics generally categorise writing assessment into dimensions that either address local concerns or global concerns. Local concerns deal with grammatical and lexical issues and are more important for writers at lower L2 proficiencies. As the student's L2 proficiency increases, global writing concerns become more pertinent. This is also the case when progressing from being a novice writer to an expert one where the writer transitions from knowledge-telling to knowledge-transforming to knowledge-crafting (Kellogg, 2008). As PhD students should have both high language writing proficiency and expertise, their global writing concerns should far outweigh their local writing concerns. Consequently, teacher instruction should guide PhD students to focus their feedback comments on global concerns and this is advocated by other researchers (Leijen, 2017; Liu \& Sadler, 2003).

In a university context, rubrics aimed at undergraduate and postgraduate students place a much greater emphasis on global concerns and categorise these concerns into dimensions such as Focus, Evidence, Organisation, Flow and Insight (Cho, Schunn \& Wilson, 2006; Moxley, 2013). There are also tailor-made online peer feedback systems (e.g. MyReviewers and Peerceptiv) that allow the instructors to select a suitable rubric for the reviewers to base their written feedback on (see Appendix A for one example of a rubric used with MyReviewers). Unlike CLs, though, rubrics tend to define the reviewing criteria to the whole group rather than to the individual. With rubrics, there is little scope for authors to give specific, tailor-made, and personalised reviewing instructions that can only be applied to one particular draft. CLs, on the other hand, can allow authors to provide background information (e.g. 'This is a raw draft about ...'), invite comments on specific textual aspects (e.g. 'Is this sentence relevant to the study?'), and encourage authors to express their individuality through the use of affective language (e.g. 'Thank you for the feedback comments.'). Consequently, CLs may help the reviewers to provide personalised feedback that meets the author's expectations. In addition, CLs can also encourage the use of social presence within dyadic feedback exchanges and this social presence may help the writing group develop a deeper sense of writing community. 


\section{Affect in the peer feedback process}

There are many researchers who stress the importance of building effective online learning communities. They argue that students who have a sense of belonging, presence, and connectedness within the community will interact comfortably with their peers and instructors, and these interactions will facilitate critical thinking within the community (e.g. Beldarrain, 2006; Garrison, Anderson and Archer, 1999; Thurston, 2005, p. 366; White, 2005). Affect within written feedback comments can benefit the peer feedback process by helping each member build a sense of community within their writing group (e.g. Lam et al., 2019). Using the same logic, it follows that affect in CLs should also help to build and sustain connectedness within writing groups.

Affective language in CLs can be measured using a taxonomy derived from social presence theory (see Short, Williams and Christie, 1976, for concise treatment of construct). Social presence is 'the ability of participants to project themselves socially and emotionally, as real people (i.e., their personality), through the medium of communication being used.' (Garrison, Anderson \& Archer 1999: 94). In this context, social presence refers to the affective language the authors use in their CLs to the other group members. A high social presence can help promote a sense of writing community and a sense of community within doctorate writing groups can enhance higher order thinking skills (Cahusac de Caux et al., 2017; Lam et al., 2019; Maher et al., 2008). Thus, a high social presence promotes a high cognitive presence. This is one of the main principles of Garrison, Anderson and Archer's (2010) Community of Inquiry model and this model can be used to facilitate higher order thinking in doctorate writing groups. Social presence can be measured through developed taxonomies (Rourke et al., 1999; Shea et al., 2010) and one has been devised specifically to measure social presence in doctorate writing groups (Yallop, 2016, p. 295).

\section{Writing instruction and research papers}

There is often much institutional pressure put on PhD students to publish their findings in research papers (Aitchison and Lee, 2006) and often PhD students have to write in English as their second language. It is also possible in some geographical regions, such as in Finland, for students to obtain their doctorate degree through a series of published articles rather than the traditional monograph (Pyhältö et al., 2019, p. 3). This situation is also the case in Estonia. Writing a scientific article for publication is demanding and many $\mathrm{PhD}$ students require instructional help to understand how to write these types of research papers (Cotos, Link \& Huffman, 2016). Consequently, many universities, including ours, adopt a process genre approach to teaching where the students are taught about the structures and rhetorical moves used within research papers in their particular scientific discipline.

Typically, research papers follow some format of the ILMRDC (Introduction, Literature Review, Methods, Results, Discussion and Conclusion) structure that may merge or exclude certain sections (Lin \& Evans, 2012). Within each section of the research paper, authors perform certain rhetorical moves in order to fulfil a particular writing purpose (see Cotos, Link \& Huffman, 2016; Lin \& Evans, 2012; Ruiying \& Allison, 2003, for concise treatments) and these rhetorical moves can be taught directly to the students. One common example of a rhetorical move is the three-method sequence outlined in Swales' (1990) 'Create a Research Space' (CARS) model that authors often follow when writing their introduction to a research paper. On courses that adopt such a genre approach, authors may make explicit references to how certain rhetorical moves (e.g. 'CARS model') may apply to their drafts in their CLs. These references to rhetorical moves could be construed as implicit evidence of transfer of teaching instruction. Similarly to social presence, Garrison, Anderson and Archer's (1999) Community of Inquiry model also posits that a high teaching presence promotes a high cognitive presence and one measurable indicator of teaching presence is evidence of teaching instruction (Shea et al., 2010, p. 19). Consequently, this study uses quantitative indicators to measure the amount of teaching instruction the participants refer to in their CLs in order to gauge the influence of course instruction on the peer feedback process. 
In addition to teaching instruction, reviewer competency is another factor that may impact the usefulness of rubrics and CLs. Interpreting and giving consistent feedback from rubrics can require considerable student training. For example, Li and Lindsey (2015) found that students on a first-year university composition course often failed to understand, or even recognise, the keywords within rubrics. These misunderstandings often led to large discrepancies between how different peers gave feedback on each other's drafts. CLs, on the other hand, may help to improve communication between the author and his/her reviewers. There is evidence that reviewers within doctorate writing groups appreciate and carefully adhere to the instructions within CLs (Yallop, 2016; Yallop, 2017; Yallop \& Leijen, 2018; Yallop, Taremaa \& Leijen, in press). The reviewers appreciate CLs because it helps them generate useful feedback comments. Similarly, authors expect their reviewers to answer their written requests for help in their CLs (Yallop, Taremaa \& Leijen, in press). Thus, CLs can help reviewers write feedback comments that meet their authors' expectations.

\section{Research questions}

The purpose of this study is to investigate whether author-devised CLs can help reviewers generate more useful feedback comments than would be attained through the use of instructordevised rubrics. In order to achieve this, the content of CLs produced by PhD students are compared to the content of one instructor-devised rubric used within the online peer feedback system MyReviewers (see Appendix A). From obtaining a better understanding of what authors write in their CLs and the potential reflective benefits to the author of writing a CL, the study further investigates whether teaching instruction can help PhD students communicate their feedback expectations more clearly to their reviewers. Thus, the two research questions that guide this study evolved as follows:

1. What are the affordances of using author-devised CLs as compared to instructordevised writing assessment rubrics within the peer feedback process? ${ }^{3}$

2. How do two separate course instructions influence the content of CLs?

\section{Course background}

This section explains the background, similarities, and differences between how two academic writing for scientific publication courses were conducted at one Estonian university. The first course took place in 2014 and involved minimal CL instruction (Course2014). The other course took place in 2019 and included explicit CL instruction (Course2019).

\section{Overview of research design}

This research is based upon the analysis of CLs written by 20 pairs of matched PhD students. One paired student attended an academic writing for scientific publication course in 2014. The other paired student attended a similar course in 2019. The students who attended the earlier course received minimal instruction on how to compose CLs. As research suggested that CLs can strongly influence the type and nature of generated feedback comments (e.g. Yallop \& Leijen, 2018), later courses placed a much stronger emphasis on the importance of the CL. Consequently, the paired student who attended the course in 2019 received extensive instruction on how to compose a CL. The data were obtained and analysed in a naturalistic context in which the lead researcher was unconnected to both courses. Thus, the lead researcher could not exert any influence on the students' attitudes towards the usefulness of CLs. Generally speaking, though format and delivery differed, both courses adopted the same principles and pedagogic aims.

Informed consent was obtained from the adult participants prior to the study to use their data anonymously for this research. All examples of CLs and participant quotes within this article's

${ }^{3}$ The authors acknowledge that there are different affordances offered by instructor-devised writing assessment rubrics. Although comparing CLs to multiple rubrics would offer more research insights, it would also over-complicate the study. Thus a representative rubric from the online peer feedback system MyReviewers was compared to CLs to answer this research question. 
figures and body text have been reproduced (with their identifying features removed) with the participants' full consent.

\section{Academic writing for scientific publication courses}

At our Estonian university, PhD students are taught to support one another's writing process by periodically giving and receiving feedback on each other's drafts within small discipline-specific writing groups. The writing courses have been continuously developed over a six-year period and, until recently, had been run annually during the three-month autumn semester. The aim of these writing courses is to support PhD students in writing a scientific article for publication. Most academic disciplines require research articles to follow some variation of the ILMRDC structure (see Lin and Evans, 2012, for concise overview). Thus, the writing lecturers have adopted a John Swales' (e.g. Swales, 1990) genre approach in which a large component of the teaching instruction focuses on helping students identify commonly used rhetorical moves in the different sections of their discipline-specific research articles.

Demand for these courses is high (typically between 40 and 90 participants) with the students coming from a wide range of disciplines from the humanities, the social sciences, and the formal sciences with a relatively even distribution of home to international students. Depending on the discipline, this is either a compulsory (mainly in the social sciences and humanities) or voluntary (mainly in the formal sciences) course that PhD students typically enrol in towards the start of their doctorate studies. The course is open to all PhD students who on successful completion of the course earn credit points towards their doctorate degree. Thus, PhD students take this course once only during their studies. Regarding publication language, the vast majority of the participants publish their research in English (mostly as their L2) and the remainder usually publish in Estonian as their mother tongue. Although these courses are being constantly improved based on student feedback and research findings, the general procedure for the peer feedback process has remained relatively unchanged throughout the years.

\section{Peer feedback process}

The students are placed into small writing groups of ideally between four and five participants based primarily on discipline and secondarily working language (L1 Estonian or L2 English) or publication language (L1 Estonian or L2 English). For the first stage of the process, the students write and upload their draft introduction and CL, typically as an MS Word document, to the group's online writing folder for review by their group members (see Fig. 1).

\section{Course Procedure}

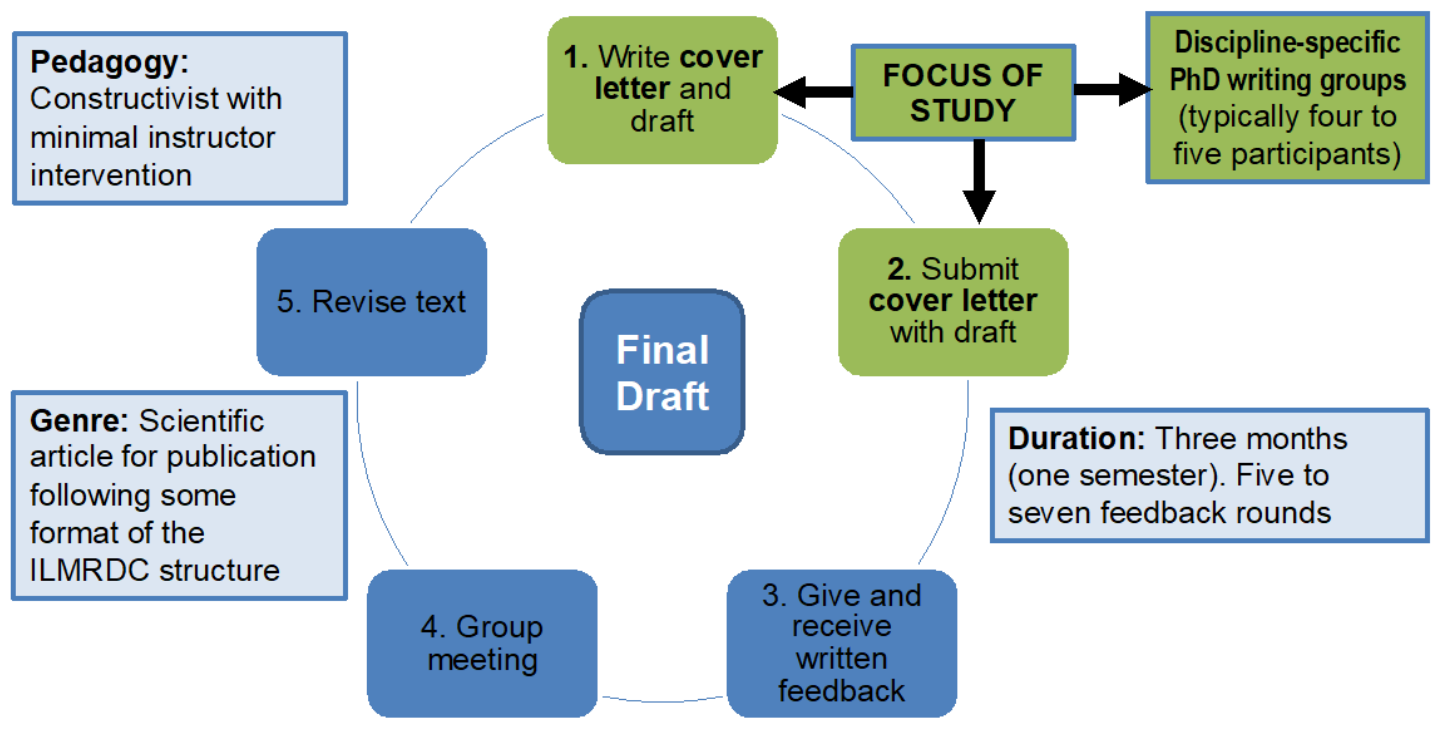

Figure 1. Schematic diagram of the peer feedback process 
Next, each group member downloads these drafts from the group folder. Then, the group members give written feedback comments, usually as text boxes, to the other group member's drafts and upload these reviewed drafts back to the group's online folder. Thus, in a writing group consisting of four participants, student A would give written feedback to students $B, C$ and $D$ and receive written feedback from students $B, C$ and D. Finally, the students meet for a face-to-face writing group meeting that is conducted according to a standardised procedure as suggested by Mikkelsen (2010). Here, each group member takes it in turn to give oral feedback to the reviewer within an allotted time period. The author is instructed to listen attentively, not to speak, and to avoid using negative body language throughout each oral review. When all the reviewers have finished speaking, the author is free to ask politely for clarification on any review aspects s/he did not understand. At the end of the group meeting, the author has to decide whether to implement, or not implement, the group's advice on how to improve his/her draft. This feedback process takes place over a three-week period. This procedure then repeats itself on a cyclic basis over a three-month period until the students have completed, or almost completed, an article for scientific publication. It is assumed that PhD students should be autonomous learners with high levels of both intrinsic and extrinsic motivation. As such, the course pedagogy is based within a strongly constructivist paradigm and there is no formal assessment of the students' drafts. Students pass the course solely on the timely submission of their drafts and reviews to their other group members. Thus, the two courses were similar regarding level, disciplines, purpose, writing assignment, instruction content, course duration, writing group division, and writing group size (see Table 2).

Table 2. Similarities between Course2014 and Course2019

\begin{tabular}{ll}
\hline Course similarities & Course2014 and Course2019 \\
\hline Level & PhD students \\
Disciplines & Social sciences, humanities, formal sciences, technology, and \\
engineering \\
Purpose & Writing a scientific article for publication \\
Article structure & Based mainly on ILMRDC structure (Lin and Evans, 2012) \\
Instruction content & Genre approach (Swales, 1990) \\
Duration & Three months (one semester) \\
Writing group (division) & By discipline; then by working or publication language \\
Writing group (size) & Four to five students (Course2019) \\
& Three to seven students; median and mode of four students \\
& (Course2014) \\
\hline
\end{tabular}

The main differences between the two courses concerned their mode of instruction, teaching resources, the content of the input, the number of feedback rounds, and the number of participants and subsequent writing groups (see Table 3).

Table 3. Differences between Course2014 and Course2019

\begin{tabular}{lll}
\hline Course difference & Course2014 & Course2019 \\
\hline Teaching format & Lectures & Workshops \\
Instructors & 1 & 3 \\
Online support & Minimal & Yes \\
CL instruction & Minimal & Yes \\
Feedback rounds & 7 & 5 \\
Participants & 90 & 40 \\
Writing groups (different disciplines) & 19 & 9 \\
\hline
\end{tabular}

These course differences have been primarily caused by the advances in technology. This means that the courses are being delivered via a more blended approach with the students receiving input through workshops and an online website, rather than from the traditional face- 
to-face lectures as was common practice in earlier years. In addition, the number of feedback rounds has been reduced from seven to five stages for practical reasons. There were also roughly twice as many participants and double as many writing groups on Course2014, as compared to Course2019, and these differences were mainly due to institutional course restructuring.

\title{
CL instruction
}

The participants of Course2014 were given approximately five-minute instruction on the role and content of the CL as well as a short CL model in their first face-to-face lecture (see Table 4). This model was also put online into the group folders.

Table 4. CL instructions given to participants on Course2014

\begin{abstract}
Cover Letters
In addition, before meeting the writing groups, you can include in your text (the one you upload in the group folder) a cover letter (see example below). The cover letter can describe the text you have uploaded and what you would like the group to review. This provides the readers with an angle when reviewing the text and ensures that the writer gets relevant input at the meeting. You can also write what is going well in your writing process and inform the group if anything special has happened since the last meeting that influences your need for feedback. You can also add dispositions and research questions to make it easier for the group to relate the selected text parts to the entire project.
\end{abstract}

\section{Example of Cover Letter:}

Dear writing group,

This text is in continuation of the text you got at the last meeting and is therefore still from my theory chapter. Last time I ended with a table which was not explained further. Therefore, I will start by explaining the table and then move on to the other parts of the theory chapter. I would particularly like feedback on whether the descriptions in the various paragraphs (and not least my hypothesis on page 3) provide an overview of the very different areas I have worked in? Or do they need to be explained further? Does it make sense?

At the moment I am working on interviews which I only have in a rough and incomplete version. But I get plenty of new ideas through this work and I feel I am on the right track. More ideas to link theory (including my table) and empirical studies are more than welcome. How do I move on from the theory to the empirical part?

See you on Friday.

The sole course instructor only minimally discussed the role of the $C L$ throughout the course. Consequently, the participants were free to write, or not to write, their CLs in any way they chose without being overly influenced by teaching instruction. In contrast, the participants of Course2019 were given clear instructions on how to construct a CL during one 45-minute workshop at the start of the course. In addition, the students were directed to the course website where these workshop slides were readily accessible. This website also contained one page of instructions on 'How to write a good cover letter' (see Appendix B).

There were three clear instructional differences that the writing instructors carefully adhered to during Course2019, as compared to Course2014. Firstly, the course instructors continually stressed the importance of including a well-composed $C L$ on the same document as the student's draft (i.e. the author's CL should be placed directly above his/her submitted draft) for peer review during each of the workshops that took place once every three weeks. Secondly, the students were inductively taught how to compose a $C L$ and this guidance was fully supported by the online materials. Thirdly, the participants were never supplied with a model $C L$ during the workshop nor in the online support materials. The second and third steps were taken for pedagogical reasons, and not for research purposes, as the course was strongly grounded in constructivism. Thus, the writing instructors of Course2019 provided more teaching 
instruction regarding the importance and appropriate content of CLs than the sole writing instructor of Course2014. However, the participants of both courses were still free to write their CLs as they wished.

\section{Methodology}

This study employs two methodologies in a mixed-method approach. Firstly, 20 participants from Course 2019 were matched with 20 participants from Course2014. The matched participants' CLs were thematically analysed using the system outlined by Braun and Clarke (2006). The resulting thematic units (TUs) were analysed quantitatively. Secondly, the participants of Course2019 were asked about their perceptions of a good CL through a postcourse questionnaire. This qualitative data was analysed within a grounded theory tradition. RQ1 is answered using a combination of the quantitative and the qualitative research methods, and the results are triangulated where possible. RQ2 was answered using only quantitative research methods.

\section{Matching participants}

Forty students from 16 different writing groups (twenty participants from Course2014 and Course2019 respectively) were matched according to scientific discipline and CL completion rate (see Table 5).

Table 5. Participants matched by discipline and writing group

\begin{tabular}{lll}
\hline \multirow{2}{*}{ Discipline } & Matched participants \\
\cline { 2 - 3 } & Course2014 & Course2019 \\
\hline Formal sciences & 10 participants & 10 participants \\
Social sciences and humanities & 10 participants & 10 participants \\
Total matched participants per course & 20 participants & 20 participants \\
CLs available for comparable analysis & $58 \mathrm{CLs}$ & $58 \mathrm{CLs}$ \\
\hline
\end{tabular}

The disciplines were divided into the formal sciences (e.g. physics) that also included engineering, and the social sciences and humanities (e.g. history and linguistics). For each comparable course, half the data was obtained from ten matched participants in four matched writing groups in the formal sciences. Similarly, the other half of the data was obtained from ten matched participants in four matched writing groups in the social sciences. In addition, the group sizes were similar in size by discipline and by course. This matching process ensured that there was an equal number of CLs produced by the 20 selected participants of Course2019 (58 CLs) and their 20 matched counterparts from Course2014 (58 CLs) available for quantitative analysis. In addition, an equal number of CLs from the matched participants were collected at three different feedback stages: the beginning (19 CLs per dataset), the middle (20 CLs per dataset) and at the end of the feedback round (19 CLs per dataset). Thus, a representative and comparable sample of CLs was collected from both Course2014 and Course2019.

\section{Thematic analysis of CLs by segmentation and categorisation}

The following quantitative methodology was used to answer both RQ1 and RQ2. The 116 CLs produced by the 20 matched participants from Course2014 and Course2019 were segmented into 987 analysable TUs according to Rourke et al.'s (1999) coding scheme for social presence. The unit of analysis was a syntactic unit of measurement of one sentence equating to one theme as advocated by Fahy (2001) and a TU (Henri, 1992) of a different syntactic unit of measurement when it seemed more logical. The mean length of one TU was 13.23 words No data was discarded in the analysis and approximately $75 \%$ of TUs were one sentence long.

The resulting 987 TUs were then categorised into one of three themes: 'Background', 'Instruction' or 'Social Presence' (see Table 6) using thematic analysis as outlined by Braun and Clarke (2006). 


\begin{tabular}{|c|c|c|}
\hline Theme & Definition of TU & Reviewer impact \\
\hline Background & $\begin{array}{l}\text { The author provides one piece of } \\
\text { background information about oneself, the } \\
\text { draft, or the target audience; typically helps } \\
\text { the reviewer generate feedback comments } \\
\text { according to the author's expectations. }\end{array}$ & $\begin{array}{l}\text { This theme can have no observable } \\
\text { direct effect, but can influence the } \\
\text { subsequent reviewer revision } \\
\text { comment(s). }\end{array}$ \\
\hline Examples & \multicolumn{2}{|c|}{$\begin{array}{l}\text { I am focusing on the Post-Soviet period; This is my current version of the methods } \\
\text { section. }\end{array}$} \\
\hline Instruction & $\begin{array}{l}\text { The author demands or suggests that a } \\
\text { response or an action is required from the } \\
\text { reviewers on one textual aspect; typically } \\
\text { includes reviewer requests for help. }\end{array}$ & $\begin{array}{l}\text { This theme can have a direct effect } \\
\text { on the nature of the subsequent } \\
\text { reviewer revision comment(s). }\end{array}$ \\
\hline Examples & \multicolumn{2}{|c|}{ Can you understand this? There is no point in reading it in detail. } \\
\hline $\begin{array}{l}\text { Social } \\
\text { Presence }\end{array}$ & $\begin{array}{l}\text { The author uses one indicator of social } \\
\text { presence (see Yallop and Leijen, 2018, for } \\
\text { concise treatment) that is affective in } \\
\text { nature. }\end{array}$ & $\begin{array}{l}\text { This theme cannot have an effect } \\
\text { on the subsequent reviewer } \\
\text { revision comments, but can cause a } \\
\text { holistic affect on the reviewing } \\
\text { process. }\end{array}$ \\
\hline Examples & \multicolumn{2}{|l|}{ Thank you for the feedback; Dear Writing Group, ... } \\
\hline
\end{tabular}

\section{Coding book for 'Background' and 'Instruction'}

Two coding books, influenced by rubrics (e.g. Moxley, 2013) and based upon the content within the 40 participants' CLs, were devised to code for sub-themes within 'Background' and 'Instruction'. These derived sub-themes can apply to both CLS and to the rubric from MyReviewers (see Table 7), or to sub-themes unique to CLs only (see Table 8). Regarding the coding book applicable to CLs and rubrics, the sub-themes 'Use of Language' and 'Generic' can apply to both rubrics and the theme 'Instruction'. There were no examples in the data to categorise these two sub-themes into the theme 'Background'. With respect to the coding book unique to CLs only, the sub-themes 'Author Mitigation', 'Draft Type' and 'Target Audience' only apply to the theme 'Background', and the sub-themes 'Reviewer Action' and 'Other' only apply to the theme 'Instruction'.

Table 7. Coding book for 'Background' and 'Instruction' (sub-themes shared by CLs and rubrics)

\begin{tabular}{|c|c|c|}
\hline $\begin{array}{l}\text { Sub-theme } \\
\text { (shared) }\end{array}$ & Definition of sub-theme & $\begin{array}{l}\text { Participant examples } \\
\text { (Background; Instruction) }^{1}\end{array}$ \\
\hline $\begin{array}{l}\text { Ideas and } \\
\text { Specifics }\end{array}$ & $\begin{array}{l}\text { The TU contains conceptual content about the } \\
\text { author's ideas; especially regarding the draft's } \\
\text { focus, logic, flow, connectedness, and readability; } \\
\text { OR } \\
\text { textual content that is specific and locatable to } \\
\text { one particular aspect or idea unit of the draft. }\end{array}$ & $\begin{array}{l}\text { This topic belongs to speciality } \\
\text { of biomedical technology; Is } \\
\text { my reasoning logical? }\end{array}$ \\
\hline Draft Length & $\begin{array}{l}\text { The TU contains textual content that relates to } \\
\text { the addition or deletion of text; including } \\
\text { references to the draft's length. }\end{array}$ & $\begin{array}{l}\text { The whole section is very large; } \\
\text { Is there anything in the } \\
\text { materials section you would } \\
\text { cut? }\end{array}$ \\
\hline
\end{tabular}


Rhetorical Moves

Coherence

and

Cohesion

Citation and

Sources

Use of

Language ${ }^{2}$
Generic $^{2}$

The TU contains functional content about the draft's aims, goals, purpose, objective, and implications (i.e. rhetorical moves).

The TU contains structural content about the organisation and structuring of the author's textual, functional, and conceptual content.

The TU contains citation-based content about the author's sources, citations, and evidence.

The TU contains language-based content about grammar, vocabulary, and other predominantly local concerns; including instructions not to comment on language-based content.

The TU contains generic content that could apply to any author's draft within any similar contexts.
The goal of this paper is to give a new perspective about ...; Are the aims of the isotope relevant?

However, the structure didn't work well and I reshaped the text; Are the paragraphs sufficiently clear?

I don't have a good bibliographic review yet; Are the contributions clear?

No example; You can feel free to comment about the grammar.

No example; Please give me useful and constructive feedback.

${ }^{1}$ Full (verbatim) or abridged examples of TUs reproduced from the participants' CLs ${ }^{2}$ Applicable only to the theme Instruction.

Table 8. Coding book for 'Background' and 'Instruction' (sub-themes unique to CLs)

\begin{tabular}{|c|c|c|}
\hline $\begin{array}{l}\text { Theme } \\
\text { Sub-theme }\end{array}$ & Definition of sub-theme & Participant examples $^{1}$ \\
\hline \multicolumn{3}{|l|}{ Background } \\
\hline $\begin{array}{l}\text { Author } \\
\text { Mitigation }\end{array}$ & $\begin{array}{l}\text { The TU contains hedging devices }{ }^{2} \text { used to } \\
\text { mitigate for author self-doubt that cannot be } \\
\text { categorised elsewhere; including mention of } \\
\text { first draft submissions. }\end{array}$ & $\begin{array}{l}\text { This part is very raw; This is my } \\
\text { first draft. }\end{array}$ \\
\hline Draft Type & $\begin{array}{l}\text { The TU contains introductory content about } \\
\text { the draft's section, genre, or version with no } \\
\text { disclosure of any textual content. }\end{array}$ & $\begin{array}{l}\text { This is the conclusion part; It is a } \\
\text { conference paper; This is a } \\
\text { revised version. }\end{array}$ \\
\hline $\begin{array}{l}\text { Target } \\
\text { Audience }\end{array}$ & $\begin{array}{l}\text { The TU contains audience-based content } \\
\text { about the target journal and intended } \\
\text { audience of the author's draft. }\end{array}$ & $\begin{array}{l}\text { The journal also publishes } \\
\text { palaeopathological papers; My } \\
\text { audience are education scientists. }\end{array}$ \\
\hline \multicolumn{3}{|l|}{ Instruction } \\
\hline $\begin{array}{l}\text { Reviewer } \\
\text { Action }\end{array}$ & $\begin{array}{l}\text { The TU contains a criterion that requires a } \\
\text { reviewer action; includes degree of allowable } \\
\text { author affect. }\end{array}$ & $\begin{array}{l}\text { You can skip reading the rest of } \\
\text { this document; I can take your } \\
\text { criticism, please be frank. }\end{array}$ \\
\hline Other & $\begin{array}{l}\text { The TU contains content that does not apply } \\
\text { to any of the themes above. }\end{array}$ & $\begin{array}{l}\text { How much do you read other } \\
\text { papers before you write? }\end{array}$ \\
\hline
\end{tabular}




\section{Coding book for 'Social Presence'}

The 987 TUs obtained from the segmentation of the 20 matched participants' CLs were inspected for indicators of social presence using a coding book adapted from Yallop's (2016) coding scheme for social presence (see Table 9). The derivation of this coding book originates from Rourke et al.'s (1999) coding scheme for social presence within Garrison, Anderson and Archer's (1999) community of inquiry model. TUs that contained indicators of social presence were further categorised into the sub-themes of 'Affective', 'Group Cohesion' and 'Open Communication' and then into their respective sub-sub themes.

Table 9. Coding book for 'Social Presence' (sub-themes and sub-sub themes)

\begin{tabular}{|c|c|c|}
\hline $\begin{array}{l}\text { Sub-theme } \\
\text { Sub-sub theme }\end{array}$ & Definition (adapted from Yallop 2016: 295). & Participant examples ${ }^{1}$ \\
\hline Affective $^{2}$ & $\begin{array}{l}\text { The author exerts their own unique personality } \\
\text { through the expression of emotions, feelings, } \\
\text { and mood; often signalled by the use of } \\
\text { personal pronouns, exclamation marks and } \\
\text { smileys. }\end{array}$ & I hope you will understand. \\
\hline $\begin{array}{l}\text { Author } \\
\text { Mitigation }\end{array}$ & $\begin{array}{l}\text { The author uses hedging devices to mitigate for } \\
\text { self-doubt that cannot be categorised } \\
\text { elsewhere. }\end{array}$ & $\begin{array}{l}\text { This is still very raw and far } \\
\text { from complete. }\end{array}$ \\
\hline Other & $\begin{array}{l}\text { The author discloses personal information to do } \\
\text { with their own personality or draft; including } \\
\text { intentions and beliefs, personal sensitivity, use } \\
\text { of humour and conspicuous punctuation. }\end{array}$ & $\begin{array}{l}\text { This is very important for } \\
\text { me; I hope to finish this } \\
\text { article with this semester ...; } \\
\text {;:) }\end{array}$ \\
\hline $\begin{array}{l}\text { Group } \\
\text { Cohesion }\end{array}$ & $\begin{array}{l}\text { The author communicates socially to the whole } \\
\text { group using conventional expressions that } \\
\text { conform to societal norms. }\end{array}$ & $\begin{array}{l}\text { Heart-felt thanks to all for } \\
\text { the (feedback). }\end{array}$ \\
\hline Openings & $\begin{array}{l}\text { The author uses a salutation at the start of the } \\
\text { CL. }\end{array}$ & $\begin{array}{l}\text { Dear Writing Group, ...; } \\
\text { Hello. }\end{array}$ \\
\hline Closures & The author uses a closure at the end of the CL. & All the best, John; Ann. \\
\hline $\begin{array}{l}\text { Expressing } \\
\text { Gratitude }\end{array}$ & $\begin{array}{l}\text { The author thanks the writing group for their } \\
\text { help. }\end{array}$ & Thank you for the feedback. \\
\hline Future Contact & $\begin{array}{l}\text { The author makes a reference to future group } \\
\text { contact. }\end{array}$ & $\begin{array}{l}\text { I am looking forward for } \\
\text { your comments. }\end{array}$ \\
\hline Phatics & $\begin{array}{l}\text { The author uses language that serves a purely } \\
\text { social purpose that cannot be categorised } \\
\text { elsewhere. }\end{array}$ & Merry Xmas to all! \\
\hline $\begin{array}{l}\text { Open } \\
\text { Communication }^{2}\end{array}$ & $\begin{array}{l}\text { The author communicates purposefully to the } \\
\text { whole group; including course practicalities, } \\
\text { apologising for failure to comply with course } \\
\text { requirements, and references to past messages. }\end{array}$ & $\begin{array}{l}\text { I am not here on Monday } \\
\text { because ...; I am late to } \\
\text { submit ...; I implemented } \\
\text { your suggested changes. }\end{array}$ \\
\hline \multicolumn{3}{|c|}{$\begin{array}{l}{ }^{1} \text { Full (verbatim) or abridged examples of TUs taken from the participants' CLs. } \\
\text { 2TUs of Affective (and occasionally of Open Communication) can also be dual-coded within the sub-themes of } \\
\text { Background or Instruction. } \\
\text { 3Only TUs coded as Social Presence can be coded within the sub-themes of Group Cohesion. }\end{array}$} \\
\hline
\end{tabular}




\title{
Coding reliability
}

A system of consensual assessment was used to ensure that the data within the CLs was coded reliably. The lead researcher segmented and coded the data, developed the coding books, and explained the system to an impartial researcher. The impartial researcher applied the coding scheme on $20 \%$ of the data. Any discrepancies between the coders were discussed and the coding was revised accordingly. This procedure was repeated five times until all the data had been coded.

\section{Grounded theory analysis conducted on the post-course questionnaires}

A qualitative methodology was used to obtain further insight into what affordances CLs can offer to the feedback process that cannot be attained by using instructor-devised rubrics. A grounded theory approach was selected to minimise researcher bias during the questionnaire design and its subsequent analysis, and to prevent the researcher being further influenced by the results of the thematic analysis of the participants' CLs. As such, this approach ensured that conclusions drawn from the questionnaires could only have been induced from the data.

The participants of Course2019 gave their perceptions about the peer feedback process in a post-course questionnaire. This section describes the rationale behind the questionnaire and how the respondents' answers were analysed within a grounded theory tradition.

All 20 participants of Course2019 completed a short online questionnaire using the software programme Google Forms during a one-week period after the course had ended. The questionnaire contained two questions designed to elicit impartial participant opinions about the role of CLs in the feedback process. The first question was a closed question with prompts for a more detailed answer and the second question was open-ended. The instructions were kept brief and non-leading (see Fig. 2).

Please consider the cover letters you wrote and received on this course and answer the two questions below.

Please take as little or as much time as you need. There is no word limit for your answer.

\section{Did writing a cover letter help you to improve your draft? (Why? Why not?)} *

The cover letter helped me when I was in a stage of writing where I had myself clear questions or problems that I could put to my group. E.g, in the last session I had written a part that was clear and focused but it was too short. So I could ask my group for suggestions. They gave me specific advice on what parts to elaborate. At the beginning of the course I felt that I wasn't happy with anything I wrote and so any kind of feedback is helpful so I couldn't state anything specific in the cover letter.

\section{What is a good cover letter? *}

\begin{abstract}
A good cover letter indicates generally what kind of text I am going to read and who will be the actual readers of the article (the audience). I liked when the cover letter was not too long, was written in a friendly tone and stated straightforwardly what the author asks me to do, even if it is only "you can comment on anything that you notice". Also, it was helpful if for a longer or complicated text the author set the focus on which parts or paragraphs to concentrate. I was in a group where the texts were really specific and not from my field so just reading the text through and making sense of it took a long time. So help from the author was appreciated.
\end{abstract}

Figure 2. Questionnaire design and example of participant response 
The data was analysed using a grounded theory approach through a combination of open, axial and selective coding (Strauss and Corbin 1997). The induced results, as appropriate, were triangulated with the findings of the thematic analysis of the participants' CLs to further inform the study's research questions. To ensure data robustness, a system of consensual assessment was employed using a similar procedure as described previously when coding the participants' CLs. However, as the data set was small, the lead researcher induced categories from the data and explained the rationale behind these categories to the second author. Then, the second author applied this coding scheme on the whole data. Any discrepancies between the two coders were discussed and the categories were amended until both coders reached agreement.

\section{Coding book for teaching instruction}

This sub-section explains how the coding books (see Tables 6, 7, 8, and 9) were applied during thematic analysis to more specifically address RQ2. As the datasets were reasonably small, only descriptive statistical analysis was conducted on each comparable dataset when determining the influence of teaching instruction between the 20 matched participants of Course2014 and Course2019.

Six teaching instruction indicators were used to measure the influence of teaching instruction on the content of CLs between the PhD students who received minimal $\mathrm{CL}$ instruction (Course2014) and the PhD students who received extensive CL instruction (Course2019) (see Table 10).

Table 10. Indicators of teaching instruction

\begin{tabular}{|c|c|c|c|}
\hline \multirow{2}{*}{\multicolumn{2}{|c|}{$\begin{array}{l}\text { Teaching instruction indicator } \\
\text { (theme, sub-theme or other) }\end{array}$}} & \multicolumn{2}{|c|}{ Comparison (Course2014 Vs Course2019) } \\
\hline & & \multirow{2}{*}{$\begin{array}{c}\text { Unit } \\
\%\end{array}$} & \multirow{2}{*}{$\begin{array}{l}\text { Desirable trend in comparable course } \\
\text { Higher } \mathrm{CL} \text { completion rate }\end{array}$} \\
\hline A1 & $\mathrm{CL}$ completion rate (other) & & \\
\hline A2 & $\begin{array}{l}\text { Background and Instruction (themes; see } \\
\text { Table 6) }\end{array}$ & TUs & $\begin{array}{l}\text { More TUs of Background and } \\
\text { Instruction }\end{array}$ \\
\hline A3 & Rhetorical Moves (sub-theme; see Table 7) & TUs & More TUs of Rhetorical Moves \\
\hline A4 & $\begin{array}{l}\text { Explicit Reference to Teaching Materials } \\
\text { (other) }\end{array}$ & TUs & More TUs of Teaching Materials \\
\hline A5 & Target Audience (sub-theme; see Table 8) & TUs & More TUs of Target Audience \\
\hline A6 & Author Mitigation (sub-theme; see Table 9) & TUs & Less TUs of Author Mitigation \\
\hline
\end{tabular}

Four indicators of teaching instruction had already been derived from the thematic analysis of the participants' CLs (A2, A3, A5 and A6 in Table 10), one indicator was determined from further thematic analysis (A4) and the results verified through a system of consensual assessment, and the other indicator (A1) was calculated from the inspection of CLs written by the whole cohort of PhD students on both Course2014 (90 participants) and Course2019 (40 participants).

\section{Assumptions in determining indicators of teaching instruction}

When comparing the two datasets, the following assumptions were made in determining the desirable trend of each indicator of teaching instruction. Firstly, submitted drafts that include a $\mathrm{CL}$ for peer review will generate more effective feedback comments than submitted drafts without CLs (A1 as denoted in Table 11). Secondly, CLs that contain a reasonable number of TUs of 'Background' and 'Instruction' are more informative than very short CLs that contain very few indicators of these two themes (A2; see Table 8 for coding scheme). Although overly long CLs may also have a negative impact on the feedback process, manual inspection of the data revealed that very short CLs (e.g. under 50 words) were much more common than very long CLs (e.g. over 300 words). As such, the indicator A2 was used as a comparative measure of teaching instruction. Thirdly, CLs that contain more references to the taught course materials (A3, 'Rhetorical Moves'; see Table 8 for coding scheme), make explicit references to other teaching materials not coded as 'Rhetorical Moves' (A4), or define their 'Target Audience' (A5) show possible evidence of a greater transfer of teaching instruction than in CLs that contain 
fewer of these indicators. Finally, and on the premise that teaching instruction should aim to increase the students' confidence in the peer feedback process, CLs that contain fewer mitigating devices signal a greater degree of author confidence in the feedback process as compared to CLs that contain many mitigating devices (A5, see Table 9 for coding scheme). Thus, and even when allowing for individual differences in affect, cohorts that use fewer mitigation devices in their CLs are more likely to have been swayed by direct course instruction than cohorts that use more mitigation devices.

\section{Results}

This section presents the results obtained from applying the methodologies in order to answer the study's two research questions.

\section{RQ1. What are the affordances of using author-devised CLs as compared to instructor-devised writing assessment rubrics within the peer feedback process?}

The following sub-section presents the results relevant to RQ1. The thematic content of the 40 participants' CLs is presented graphically and compared to the thematic content of one rubric used with the online feedback system MyReviewers (see Appendix B). Based on this thematic analysis, a representative example of an average participant CL is induced from the data. This sub-section concludes by presenting the induced results from the online questionnaire (from Course2019 only) about how CLs can benefit the peer feedback process.

\section{TUs by themes ('Background', 'Instruction' and 'Social Presence')}

Application of the coding books resulted in the following distribution of TUs by overarching theme (see Fig. 3). The yellow bars on the right-hand side of the figure show the number of TUs dual-coded as both 'Social Presence' and as 'Background', or as 'Social Presence' and as 'Instruction'.

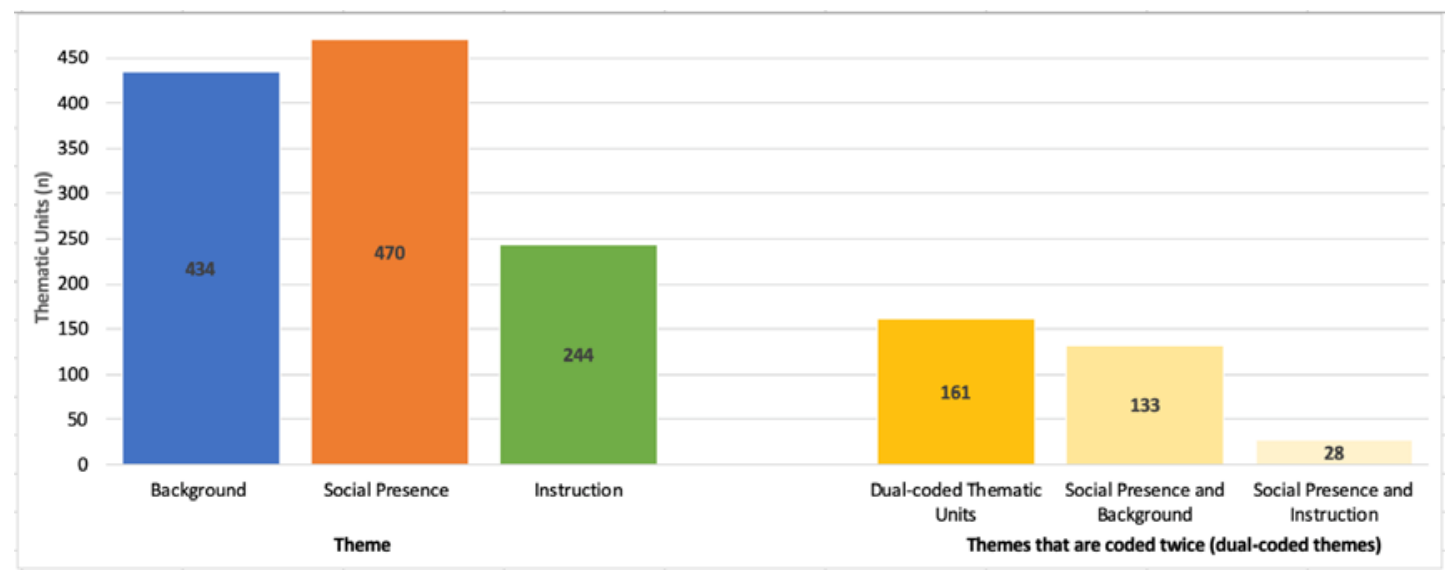

Figure 3. Distribution by theme of 987 TUs (including dual-coded TUs)

Out of a total of 987 TUs obtained from 116 CLs, 434 TUs (44\%) contain background textual aspects, 470 TUs (48\%) have indicators of social presence, and 244 TUs (25\%) are comprised of requests for reviewer help (i.e. 'Instruction'). 86 TUs (11\%) were dual coded as both 'Background' and 'Social Presence', and a small number (eight TUs) were categorised as 'Instruction' and 'Social Presence'. Thus, the proportional distribution of TUs within an average CL roughly approximated to two TUs of 'Social Presence' to two TUs of 'Background' to one TU of 'Instruction'. 


\section{TUs by 'Background' and 'Instruction' (combined)}

The resulting 678 TUs of 'Background' and 'Instruction' were further categorised into subthemes. These sub-themes are shown as a combination of both 'Background' and 'Instruction' (see Fig. 4).

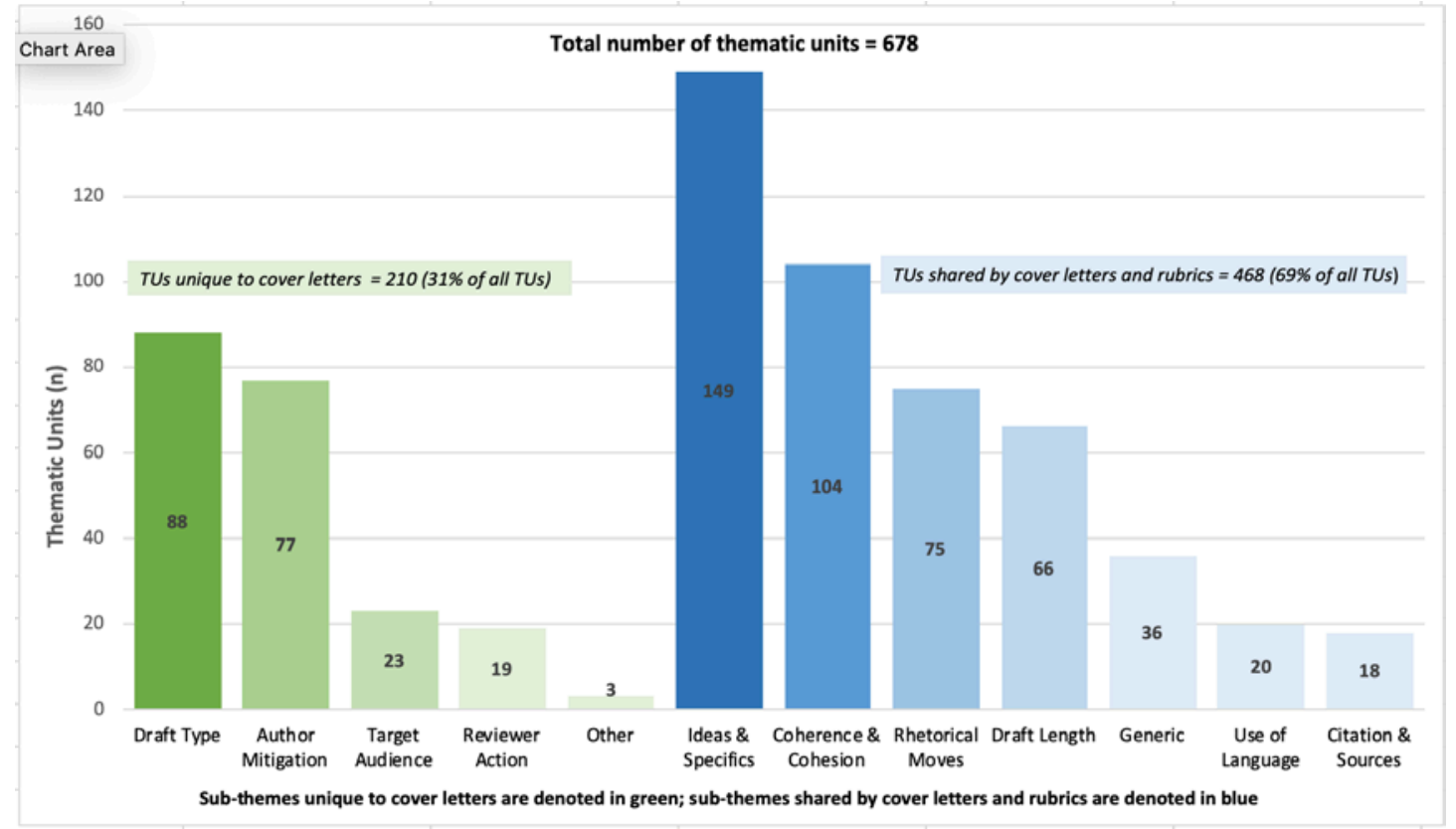

Figure 4. Distribution of TUs in CLs by Background and Instruction

This revealed that 210 TUs ( $31 \%$ of all TUs) could not be represented using rubrics (represented in green) and 468 TUs (69\% of all TUs) could be expressed by rubrics (represented in blue). Regarding the themes unique only to CLs, 'Draft Type' (88 TUs) and 'Author Mitigation'4 (77 TUs) contained by far the most TUs. Other themes that cannot be represented by rubrics (45 TUs) mainly consisted of 'Target Audience' (e.g. 'The audience are educationists') and 'Reviewer Action' (e.g. 'Please be as straightforward as you like.').

With respect to the themes shared by both CLs and rubrics, the largest number of TUs are coded as 'Ideas and Specifics' (149 TUs), followed by 'Coherence and Cohesion' (104 TUs), 'Rhetorical Moves' (75 TUs) and 'Draft Length' (66 TUs). The least commonly used themes are 'Generic' (36 TUs), 'Use of Language' (20 TUs), and 'Citation and Sources' (18 TUs).

\section{TUs by 'Social Presence'}

The 427 TUs of 'Social Presence' were sorted into sub-themes and their respective sub-sub themes (see Fig. 5).

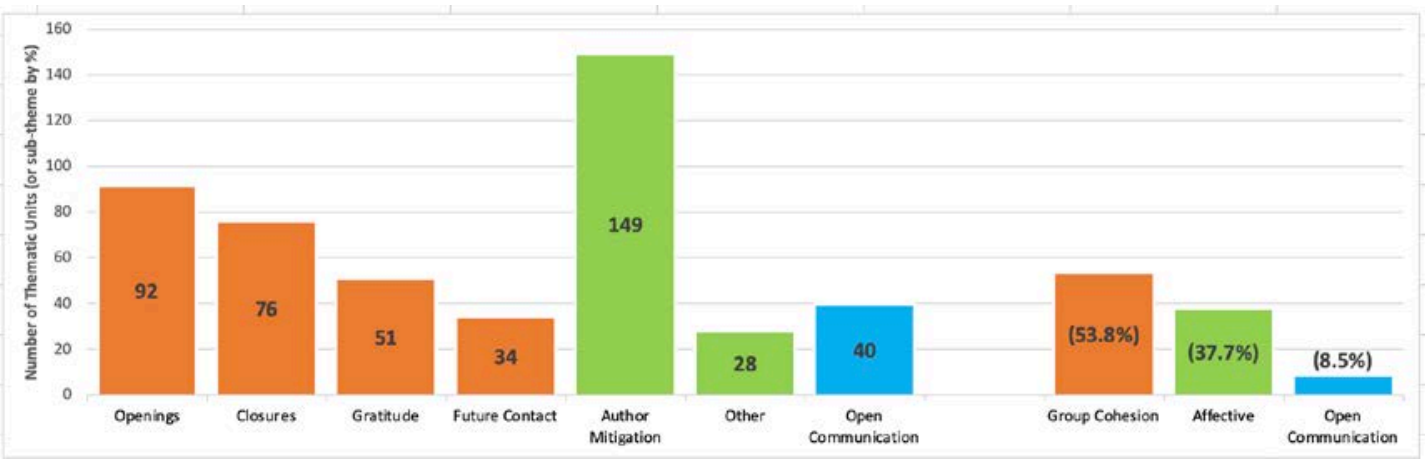

Figure 5. Distribution of TUs in CLs by Social Presence

${ }^{4}$ Note that 'Author Mitigation' is dual coded as both 'Social Presence' and as 'Background'. 
A little over half of the 427 TUs are categorised as 'Group Cohesion' where the authors frequently used 'Openings' and 'Closures' (92 TUs), expressed 'Gratitude' for their feedback comments (51 TUs), or made references to 'Future Contact' to their writing group (34TUs). Approximately one-third of TUs are coded as 'Affective', with 'Author Mitigation' (149 TUs) being used the most frequently. 'Other' (28 TUs) refers mainly to the author expressing intention (e.g. 'I will do this later.'). A much smaller proportion of TUs (40 TUs) relate to 'Open Communication' where the authors engaged in meaningful communication (e.g. 'I cannot give feedback next week because ...').

\section{Sequential usage of dimensions within CLS}

The 116 CLs were examined for a common pattern concerning the sequential use of their content. Statistical analysis ${ }^{5}$ revealed that the mean length of a CL was 8.5 TUs and the mode was seven TUs within $20 \mathrm{CLs}$. Analysis of these $20 \mathrm{CLs}$ revealed a diverse range of the sequence and usage of the themes 'Background', 'Instruction' and 'Social Presence'. Thus, the search criteria were expanded to all CLs that contained a reasonable number of TUs (i.e. neither too few nor too many TUs) within a larger sample of the data. This resulted in the inspection of 70 CLs (i.e. $60 \%$ of the data) containing between six and eleven TUs until a common trend emerged (see Fig. 6).

\begin{tabular}{|c|c|c|c|c|c|c|c|c|c|c|c|c|c|c|c|}
\hline CL & TU1 & TU2 & TU3 & TU 4 & Tu5 & TU6 & Tu7 & TU8 & TU9 & TU 10 & TU11 & Average Cover letter ${ }^{1}$ & Dimension & Theme & Sequence \\
\hline 1 & SP & в & B & BSP & 1 & SP & & & & & & \multirow{2}{*}{ Dear Writing Group, } & \multirow{2}{*}{$\begin{array}{l}\text { Social } \\
\text { Presence }\end{array}$} & \multirow{2}{*}{$\begin{array}{l}\text { Group } \\
\text { Cohesion } \\
\text { Openings }\end{array}$} & \multirow{2}{*}{ TU1 } \\
\hline 2 & $\mathrm{sP}$ & $\mathrm{SP}$ & BSP & в & 1 & SP & & & & & & & & & \\
\hline 3 & SP & BSP & 1 & 1 & 1 & SP & SP & & & & & \multirow{2}{*}{ This is still very raw and far from complete, } & \multirow{2}{*}{$\begin{array}{l}\text { Background } \\
\text { AND Social } \\
\text { presence }^{2}\end{array}$} & \multirow{2}{*}{$\begin{array}{l}\text { Author } \\
\text { Mitigation }\end{array}$} & \multirow{2}{*}{ TU2 } \\
\hline 4 & SP & BSP & BSP & 1 & 1 & SP & SP & & & & & & & & \\
\hline 5 & SP & BSP & 1 & BSP & BSP & SP & SP & & & & & \multirow{2}{*}{ It is a second draft of the introduction section } & \multirow{2}{*}{ Background } & \multirow{2}{*}{ Draft Type } & \multirow{2}{*}{ TU3 } \\
\hline 6 & $S P$ & B & BSP & 1 & 1 & 1 & SP & & & & & & & & \\
\hline 7 & SP & BSP & в & 1 & 1 & 1 & SP & & & & & \multirow{3}{*}{$\begin{array}{l}\text { It will describe the validation and psychometric } \\
\text { properties of the Estonian version of the Alcohol Quality } \\
\text { of Life Scale. }\end{array}$} & \multirow{3}{*}{ Background } & \multirow{3}{*}{$\begin{array}{l}\text { Ideas and } \\
\text { Specifics }\end{array}$} & \multirow{3}{*}{ TU4 } \\
\hline 8 & SP & B & BSP & в & в & I & SP & & & & & & & & \\
\hline 9 & SP & BSP & B & B & B & 1 & SP & & & & & & & & \\
\hline 10 & SP & BSP & 1 & 1 & 1 & SP & SP & SP & & & & \multirow{3}{*}{$\begin{array}{l}\text { Also, you will notice that the structure is very different } \\
\text { than the one that was presented in class. }\end{array}$} & \multirow{3}{*}{ Background } & \multirow{3}{*}{$\begin{array}{l}\text { Coherence } \\
\text { and } \\
\text { Cohesion }\end{array}$} & \multirow{3}{*}{ TU5 } \\
\hline 11 & SP & B & B & 1 & 1 & ISP & SP & SP & & & & & & & \\
\hline 12 & SP & B & B & 1 & 1 & 1 & SP & SP & & & & & & & \\
\hline 13 & SP & B & B & в & B & 1 & 1 & SP & & & & \multirow{2}{*}{$\begin{array}{l}\text { What I would like you to look for are the steps proposed } \\
\text { by the lecturers that make an introduction a whole. }\end{array}$} & \multirow{2}{*}{ Instruction } & \multirow{2}{*}{$\begin{array}{l}\text { Rhetorical } \\
\text { Moves }\end{array}$} & \multirow{2}{*}{ TU6 } \\
\hline 14 & SP & B & BSP & 1 & 1 & BSP & SP & SP & SP & & & & & & \\
\hline 15 & $\mathrm{SP}$ & B & в & B & 1 & 1 & 1 & SP & SP & & & \multirow{2}{*}{ Any (other) comments are very much appreciated. } & \multirow{2}{*}{ Instruction } & \multirow{2}{*}{ Generic } & \multirow{2}{*}{ TU7 } \\
\hline 16 & SP & B & BSP & B & B & B & 1 & SP & SP & $S P$ & & & & & \\
\hline 17 & SP & B & B & B & B & 1 & 1 & 1 & SP & SP & & \multirow{2}{*}{ Thank you for feedbackl } & \multirow{2}{*}{$\begin{array}{l}\text { Social } \\
\text { Presence }\end{array}$} & Group & \\
\hline 18 & SP & B & B & B & B & B & 1 & 1 & 1 & SP & SP & & & Gratitude & 100 \\
\hline 19 & SP & B & B & BSP & B & B & B & 1 & 1 & SP & SP & Best reards Particinant & Social & Group & TU9 \\
\hline 20 & SP & B & B & BSP & B & B & B & 1 & 1 & ISP & SP & & Hresence & Closures & \\
\hline & $\begin{array}{l}\text { o unde } \\
\text { Cover } \\
\text { Social } \\
\text { stucti }\end{array}$ & $\begin{array}{l}\text { standin } \\
\text { ttter; TU } \\
\text { resence } \\
; \text { isP }=\end{array}$ & $\begin{array}{l}g \text { abbre } \\
=\text { Then } \\
;=B=B a \\
\text { and SP }\end{array}$ & $\begin{array}{l}\text { viations } \\
\text { atic Unit } \\
\text { *ground } \\
\text { (treated }\end{array}$ & $\begin{array}{l}\text { (each b } \\
\text { Digits ! } \\
\text {; BSP = } \\
\text { as } 1 \text { the }\end{array}$ & $\begin{array}{l}\text { ox repr } \\
\text { epresen } \\
\text { B and S } \\
\text { matic u }\end{array}$ & $\begin{array}{l}\text { sents } \\
\text { seque } \\
\text { P (treat }\end{array}$ & $\begin{array}{l}\text { themat } \\
\text { to in } \mathrm{CL}\end{array}$ & & & & $\begin{array}{l}\text { 'This cover letter confoms sto the distribution of themes as foun } \\
\text { Background: } 2 \text { TU of of Social Presenco: } 1 \text { TU of Instruction } \\
\text { "This thematic unit (TU) is counted as } 1 \text { TU of Backround and }\end{array}$ & $\begin{array}{l}\text { an average cover } \\
\text { TU of Social Pre }\end{array}$ & tter, namely: 2 & \\
\hline
\end{tabular}

Figure 6. Sequence and usage of themes in selected CLS

The table on the left shows one common pattern discovered within 20 of these CLs. Orange, blue, and green boxes represent TUs of 'Social Presence', 'Background' or 'Background' and 'Social Presence', and 'Instruction' or 'Instruction' and 'Social Presence' respectively. The table on the right depicts an average CL (e.g. conforming to statistical means regarding its thematic distributions and length) and is composed of an amalgamation of the most common TUs taken from these 20 CLs.

\footnotetext{
${ }^{5}$ For simplicity, dual-coded thematic units (e.g. TUs containing both 'Background' and 'Social Presence') were treated as only one TU for the purpose of statistical analysis.
} 
This general pattern suggests that authors often start their CLs with a friendly opening ('Social Presence') where the author may also mitigate for any potential textual weaknesses ('Background' and 'Social Presence'). These themes are commonly followed by the author supplying one or more background details and then asking for reviewer help on at least one specific and/or generic textual aspect. It is also usual for authors to end their CLs with a friendly closure ('Social Presence') that may, or may not, include a reference to future contact ('Social Presence'). These inferences are further supported by the participants' post-course questionnaires.

\section{Online questionnaires}

In order to obtain qualitative evidence about the affordances of the content in CLs as compared to rubrics, the 20 participants of Course 2019 were further asked their perceptions of a useful $\mathrm{CL}$. Overall, the participants agreed that CLs should include balanced content within the three themes of 'Background', 'Instruction' and 'Social Presence', as aptly surmised by one participant:

'The cover letter should point out the key things the text is going to be about and the things you want the peers to pay attention to. It should be written in a polite manner and let the peers know that you really appreciate the feedback.' (Participant)

Regarding 'Background', reviewers appreciated being supplied with textual background about the intended audience, personal details about the author (e.g. author affect), and the context and rhetorical function of the draft (e.g. the draft's purpose). For 'Instruction', many participants stated that CLs should be "short and informative" and "ask (only a) few but good questions." The respondents further reported that requests for reviewer help should be "worded precisely and unambiguously" (i.e. unhedged) and focus on specific textual aspects with the author's expectations explicitly stated. However, and as another participant explains, this ideal was not always possible.

'At the beginning, I wasn't happy with anything I wrote and so any kind of feedback was helpful ... However, the cover letter helped me when I was in a stage of writing where I had clear questions or problems that I could put to my group.' (Participant)

Thus, authors still familiarising themselves with their writing often ask for generic rather than specific help in their initial CLs. Nevertheless, generic comments still generated useful feedback. This evidence also implies that the authors' subsequent CLs are more likely to contain specific requests for reviewer help as their writing confidence improves over time. As for 'Social Presence', two participants stated that a useful CL should be written in a friendly tone and include expressions of gratitude for reviewer help.

The participants were also indirectly asked whether the process of writing CLs helped them to improve their drafts. There were eight explicit responses related to the impact of the CL on the author's own writing process. One participant stated that "While figuring out the questions for my peers, I also had to concretely examine my work as a whole, which is something you tend to forget while you are writing." Similar sentiments were echoed by three other participants. One participant mentioned the affective benefits in that "shortcomings also lessens the worry about the feedback." and another stated that it helps "you learn to better understand your audience." Two participants did not think that writing a CL had much impact on their writing processes, but one did admit that "I didn't even think about it." Writers, though, may not always be consciously aware of their own writing processes.

RQ2. How does course instruction influence the content of participants' CLs? In order to answer RQ2, six teaching instruction indicators were used to compare the difference in teaching instruction between the two courses. The results are presented below.

\section{CL completion rate between Course2014 and Course2019}

The number of submitted drafts and the number of completed CLs for all the doctorate writing groups over all the feedback rounds for both Course2014 and Course2019 was calculated (see Table 11). 
Table 11. Comparison of completion rate of participant drafts with CLs

\begin{tabular}{|c|c|c|}
\hline Variable & Course2014 ${ }^{1}$ & Course2019² \\
\hline Completed drafts & 489 & 151 \\
\hline Drafts with CLs & 286 & 144 \\
\hline Drafts without CLs & 113 & 6 \\
\hline Completion of drafts with CLs & $71.7 \%$ & $96.6 \%$ \\
\hline $\begin{array}{l}{ }^{1} 19 \text { groups; } 86 \mathrm{PhD} \text { students; } 7 \text { feedback rounds } \\
29 \text { groups; } 38 \mathrm{PhD} \text { students; } 5 \text { feedback rounds }\end{array}$ & & \\
\hline
\end{tabular}

Authors often submitted their final and completed article to the other group members for completeness for the last feedback round of the course. In these cases, the authors intentionally did not include CLs with their final drafts because there was no need for their reviewers to give feedback on completed articles. Articles submitted for completeness were excluded in the calculation of CL completion rates for Course2014 and Course2019.

Almost the whole cohort of Course2019 (38 PhD students) wrote CLs with their submitted drafts (96.6\%) as compared to a lower CL completion rate (71.7\%) for the cohort of Course2014 (86 $\mathrm{PhD}$ students). To ensure whole and comparable data sets, the mean $\mathrm{CL}$ completion rate for the cohort of Course2019 (96.6\%) was used as the benchmark figure in selecting the 20 matched participants from Course2014. This selection process may have caused a slightly unrepresentative sample as the selected participants from Course2014 had a higher mean CL completion rate $(96.6 \%)$ than their cohort's mean $\mathrm{CL}$ completion rate $(71.7 \%)$. This possible distortion in the analysis of the results is accounted for in the discussion section.

The other five teaching instruction indicators between Course2014 and Course2019 To ensure a comparable basis between the two datasets, the following analysis uses an equivalent number of CLs produced by the twenty matched participants of Course2014 and Course 2019 at each feedback stage. This resulted in a total of 58 CLs for each dataset available for analysis.

The number of TUs within the theme 'Background' and 'Instruction', the sub-themes 'Author Mitigation', 'Rhetorical Moves' and 'Target Audience', and all 'Explicit References to Teaching Materials' in all the other TUs were used as the five other indicators of teaching instruction. The number of these teaching instruction indicators used by the 20 participants of Course2019 (represented in blue) were compared to the 20 participants of Course2014 (represented in orange) (see Fig. 7).
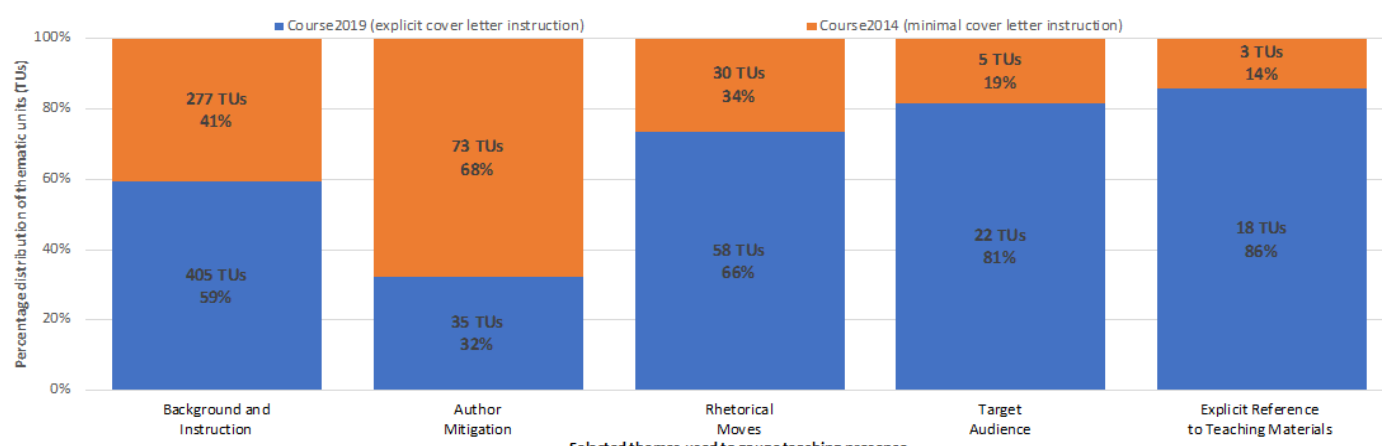

Figure 7. Comparison of TUs by course on selected themes and sub-themes

The participants who received explicit CL instruction wrote nearly 1.5 times more TUs of 'Background' and 'Instruction', approximately half fewer TUs of 'Author Mitigation', almost twice as many TUs of 'Rhetorical Moves', over four times more TUs of 'Target Audience' and made six times more 'Explicit References to Teaching Materials'. 


\section{Discussion}

\section{RQ1. What are the affordances of using author-devised CLs as compared to instructor-devised writing assessment rubrics within the peer feedback process?}

The following sub-section discusses the results relevant to RQ1 by comparing how the content within the 40 participants' CLs could be categorised, or not categorised, within one rubric used within the online peer feedback system MyReviewers (see Appendix B). The sub-section concludes by discussing the affect and possible cognitive benefits of CLs within the feedback process.

\section{TUs by 'Background' and 'Instruction'}

Approximately two-thirds of TUs can be categorised using both the example rubric and CLs. In TUs falling into this grouping, the authors focused almost exclusively on global writing concerns related to specific textual content, ideas, structure above the sentence level, rhetorical moves, and being able to compress their draft into the allowable word limit, as expert writers should (Liu and Sadler 2003). It was also rare for authors to both provide textual background details or ask for reviewer help on 'Citation and Sources'. Doctorate supervisors are competent in providing feedback on specific sources, whereas PhD students within similar fields are only proficient to give general feedback concerning sources (Yallop, Taremaa and Leijen in press). This evidence suggests that the authors may have been aware of the competencies of their peer reviewers and adjusted their content accordingly. Generic comments (e.g. 'Please provide feedback on any other issue not mentioned.') give an invitation to reviewers to provide both positive and critical feedback comments on any area that the author has not been able to predict. Thus, they serve a useful purpose. Language concerns were rare and generally the authors only asked for feedback on systematic errors that disturb the draft's readability.

Approximately one-third of TUs could not be categorised within the example rubric and were unique to CLs. The vast majority of these TUs (90\%) related to describing textual and audiencebased background details, or using hedging devices to mitigate for potential textual weaknesses. Providing introductory information about the type of draft (e.g. 'This is the methods section') or giving background about the intended audience should always help the reviewers build schematic knowledge of the author's draft in a similar way that a topic sentence can help the reader understand the main topic within the paragraph. Showing author vulnerability or coyness (e.g. 'This draft is very raw.') is more difficult to analyse within this predominantly quantitative research design. However, hedged TUs could "present the true state of the writers' understanding" (Salager-Meyer 1994: 3) so that they would act as a genuine invitation for reviewers to give critical feedback. Finally, and coded under 'Instruction', TUs of reviewer action (e.g. 'Please give me critical feedback: no sugar coating needed') act more like a wildcard in that they allow the author to set reviewing criteria, such as individual affective differences, which could not be easily specified using other assessment criteria.

\section{TUs by 'Social Presence'}

Previous feedback studies have found that between $30 \%$ to $40 \%$ of reviewers' segmented feedback comments in comparable doctorate writing groups contain indicators of 'Social Presence' (Yallop and Leijen 2018, Yallop, Taremaa and Leijen in press). This study has determined that authors use a similar amount of social presence within their CLs (contained within $43 \%$ of TUs). Researchers have shown that students as both reviewers and feedback recipients both use and value affective language in written peer feedback comments (Cho, Schunn, and Charney 2006, Gee 1972, Yallop and Leijen 2018), and this perception seems to also hold true regarding authors as self-assessment providers. Furthermore, and within a sociocultural framework, studies show that high social presence within communities of inquiry can promote cognitive presence by developing a sense of community (Cahusac de Caux et al. 2017, Garrison, Anderson and Archer 1999).

The high amount of 'Social Presence' within the authors' CLs would suggest that the majority of writing groups in this study had bonded well together to create a supportive learning environment. Writing groups that may not be functioning effectively tend to rarely disclose their 
weaknesses (e.g. author mitigation) and infrequently use other indicators of social presence such as openings and closures (Rourke et al. 1999). Thus, writing instructors can intervene in such cases where little social presence is evident within such writing groups.

\section{Affect in CLS}

There is considerable agreement between the participants' perceptions of what content should be compiled within a CL, and the participants' actual practices with regard to background information (i.e. 'Background') and requests for reviewer help (i.e. 'Instruction'). However, there were few explicit participant perceptions regarding the role of social presence. This may have been due to the unprompted nature of the questionnaire in which the participants did not consciously perceive the role of such affective language. Nevertheless, the participants used many indicators of 'Social Presence' (contained within approximately $40 \%$ of all coded TUs) within their CLs. This figure of $40 \%$ also roughly correlates to the number of indicators of 'Social Presence' found in reviewers' feedback comments in comparable doctorate writing groups (Yallop and Leijen 2018, Yallop, Taremaa and Leijen in press). These results show that students use much social presence in their written feedback exchanges, often perhaps subconsciously, and its role in the peer feedback process needs further investigation.

Cognitive benefits from the process of writing CLS.

Analysis of the online questionnaires suggests that there may be three main cognitive benefits of writing a CL on the author's own writing processes. Firstly, CLs can encourage authors to diagnose their own texts. Secondly, CLs can help authors take an audience perspective. Thirdly, CLs can allow authors to manage their own affective filters by allowing them to mitigate for any potential textual weaknesses. These findings concur with one other comparable study (Yallop, Leijen and Taremaa in press) and also have undertones to Lundstrom and Baker's (2009) study where they found that the writing processes of students who only gave written feedback improved more than those students who only received written feedback. Although this data set is small, the cognitive benefits of writing CLs do seem to exist. However, further studies are needed to confirm, or not confirm, this tentative claim.

\section{RQ2. How does course instruction influence the content of participants' CLs?} The following sub-section discusses the results relevant to RQ2.

\section{Comparison of teaching instruction indicators between Course2014 and 2019}

As expected, quantitative comparison of all six teaching instruction indicators ( $A 1, A 2, A 3, A 4$, $\mathrm{A} 5$ and $\mathrm{A6}$ ) between the two courses revealed that the $\mathrm{PhD}$ students who received explicit $\mathrm{CL}$ instruction (Course2019) exhibited more evidence of transfer of teaching instruction than the PhD students who received minimal CL instruction (Course 2014) (see Table 11). Even if these results are not surprising, measuring the frequency of specific quantitative indicators within students' CLs can serve useful purposes by helping instructors, for example, identify writing groups that appear to be struggling.

Table 11. Comparison of teaching instruction indicators between Course2014 and 2019

\begin{tabular}{lllc}
\hline \multicolumn{2}{l}{ Desirable teaching instruction indicator } & More desirable & Less desirable \\
\hline A1 & Higher CL completion rate as percentage ${ }^{1}$ of whole cohort & Course2019 & Course2014 \\
A2 & More comparable TUs ${ }^{2}$ of theme Background and Instruction & Course2019 & Course2014 \\
A3 & More comparable TUs ${ }^{2}$ of sub-theme Rhetorical Moves & Course2019 & Course2014 \\
A4 & More comparable TUs ${ }^{2}$ of References to Teaching Materials & Course2019 & Course2014 \\
A5 & More comparable TUs ${ }^{2}$ of sub-theme Target Audience & Course2019 & Course2014 \\
A6 & Less comparable TUs ${ }^{2}$ of Author Mitigation & Course2019 & Course2014 \\
\hline \multicolumn{4}{l}{${ }^{1}$ Calculated on a \% basis of all students on Course2014 (86 students) and Course 2019 (38 students). } \\
${ }^{2}$ Calculated using the 58 CLs produced by the twenty participants on Course2014 as compared to the 58 CLs \\
produced by the matched twenty participants on Course2019 during the same feedback rounds. \\
\hline
\end{tabular}

Thus, explicit $C L$ instruction is likely to lead to a higher $C L$ completion rate ( $A 1$ in Table 11). CLs also tend to be longer and more informative (A2) with more references to the taught course material (A3 and $\mathrm{A} 4)$. Explicit $\mathrm{CL}$ instruction may also help the author to take an audience 
perspective to writing (A5) and to become a more confident participant of the peer feedback process (A6). However, these desirable traits that are more pronounced with explicit $\mathrm{CL}$ instruction may also be partially attributed to the improved pedagogy on Course2019. As compared to Course2014, Course2019 had a more favourable instructional design as the course had a much higher writing instructor to student ratio, fewer feedback rounds, and the teaching material was accessible online.

On the other hand, explicit CL instruction may even accentuate these desirable traits in the participants' CLs. So as to have a comparable benchmark with Course2019, only the CLs of the 20 selected participants on Course 2014 who had a much higher CL completion rate (96\%) as compared to their cohort mean (74\%) were selected in the thematic comparative analysis of the teaching presence indicators $\mathrm{A} 2, \mathrm{~A} 3, \mathrm{~A} 4, \mathrm{~A} 5$ and $\mathrm{A} 6$. In other words, these selected participants are likely to have used a higher number of desirable teaching presence indicators in their CLs than if a more representative sample based on CL completion rates had been chosen. However, the cohort mean completion rate of CLs for Course 2019 was $96 \%$ and this benchmark figure was used to select a representative sample of participants from this cohort. In other words, the selected participants of Course2019, unlike their matched counterparts of Course2014, are more likely to have used a similar number of teaching presence indicators than any of their other cohort member would have done.

Thus, there are variables unaccounted for in this study that could weaken or strengthen the argument for giving explicit $\mathrm{CL}$ instruction within the peer feedback process. However, and despite these limitations to the study, there is still firm evidence that explicit $\mathrm{CL}$ instruction can offer many pedagogical affordances that could not be achieved through using an instructordevised assessment rubric.

\section{Comparison of content within CLs between Course 2014 and 2019.}

Frequent content about similar sub-themes (e.g. coherence and cohesion) within CLs may give an indication of the students' perceived areas of weaknesses. The participants' CLs contained much information about the focus, content, and organisation of their drafts, and few details about their use of sources and language. This trend seems to partially reflect the teaching instruction where instructors focused the students' attention on the functional use of rhetorical moves and not on the use of sources within research articles. Students were further advised to concentrate on global rather than local concerns. These results suggest that course instruction is likely to exert a noticeable influence on the content of the participants' CLs. Thus, the inspection of the content of CLS may give some indications of the quality and quantity of teaching instruction, and these indications may also help us obtain a better understanding of the students' own perceptions concerning their areas of writing weaknesses.

When comparing the participants of Course2019 to Course2014, there is strong evidence that direct $C L$ instruction has a beneficial impact on the quantity and quality of $C L$ content. Direct $\mathrm{CL}$ instruction led to a much higher proportion of completed CLs, more textual background details and requests for reviewer help, and many more references to taught material (e.g. 'Rhetorical Moves') and explanations of the target audience. As supported by Nicol, Thomson and Breslin's (2013) study, the much higher use of 'Target Audience' suggests that CL instruction may help authors develop a greater awareness of writing for an audience. Authors would also need to write a reasonably long $C L$ in order to include enough textual background details (i.e. 'Background') and requests for reviewer help (I.e. 'Instruction') to generate useful feedback comments. Although the length of a CL does not automatically make it useful, this evidence suggests that a longer $\mathrm{CL}$ is generally more informative than a shorter $\mathrm{CL}$. Regarding the last teaching instruction indicator, 'Author Mitigation', the participants of Course2019 used fewer hedging devices in their CLs than their matched participants on Course2014. Using fewer hedged CL comments may indicate a greater confidence in the authors' ability to self-devise their own feedback assessment criteria. Nevertheless, the participants of Course2019 still used an appreciable number of hedging devices in their CLs (contained within $32 \%$ of TUs). This high use of hedging devices within both comparison groups suggests that affect may play a prominent role in the written peer feedback process. 
Overall, the results indicate that direct $C L$ instruction can help authors write more informative and more confident CLS. The content of CLs is also influenced by the course input materials. Thus, explicit CL instruction can help students write useful CLs and useful CLs should help generate useful reviewer feedback comments.

\section{Conclusion: CLs versus Writing Assessment Rubrics}

This paper has examined whether CLs can be used to generate useful feedback comments in tandem with, or instead of, rubrics in the context of doctorate writing groups. This aim of the research was achieved by analysing the content of CLs produced by 20 matched PhD students at various stages of the peer feedback process and by comparing this content to one rubric used with the online peer feedback system MyReviewers. Further insights were attained by asking the participants of Course2019 about their perceptions of a 'good cover letter' through a post-course online questionnaire. The study found that CLs may offer four main affordances over rubrics and the salient points are illustrated below (see Fig. 8).

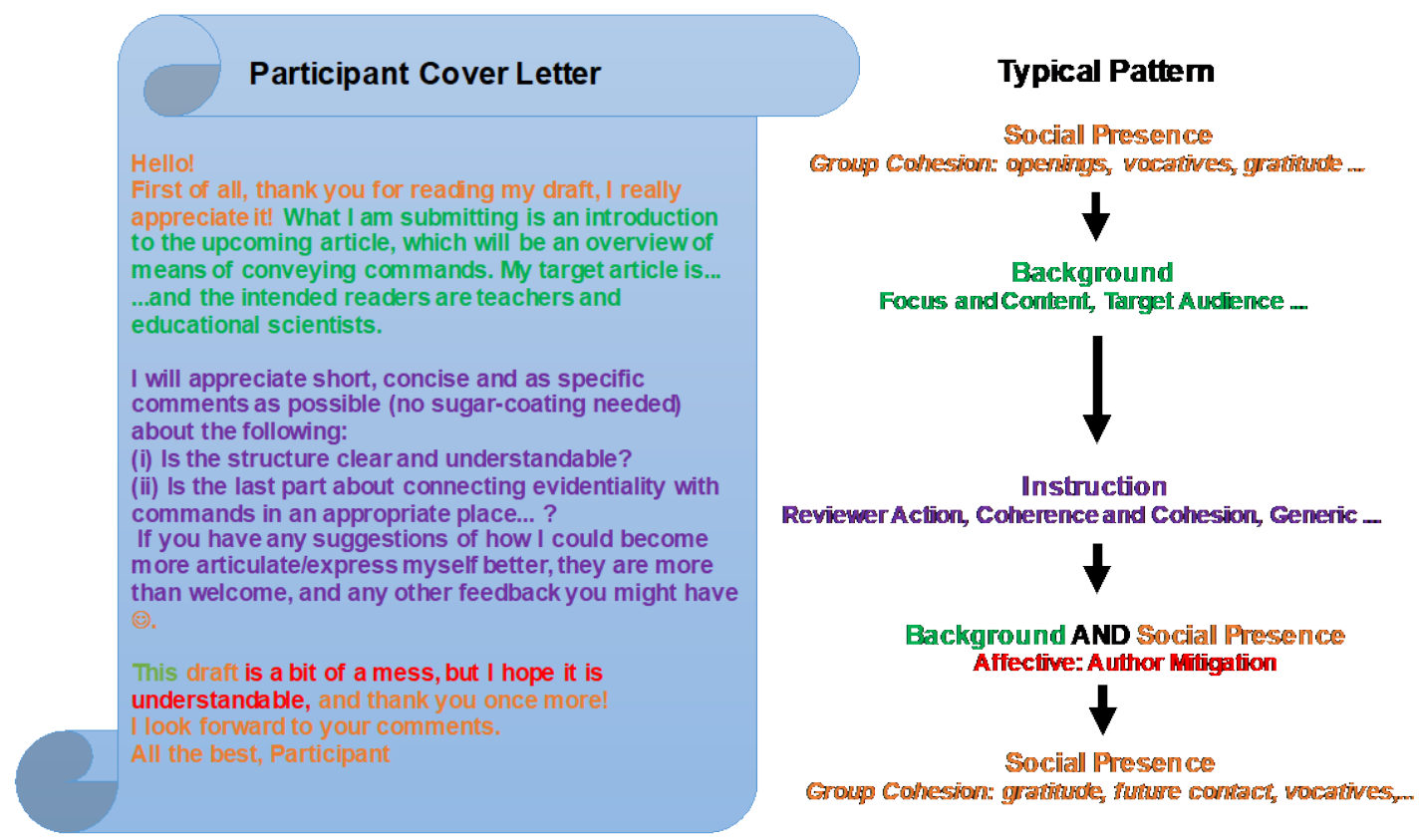

Figure 8. Example of a useful participant CL

Firstly, CLs can provide the reviewers with background information about the author, the draft, and the intended target audience. Secondly, CLs can allow the authors to seek advice on particular aspects of their draft according to their own needs. These text-specific questions can help their reviewers give tailor-made feedback that exactly meets the author's expectations. In this study, the participants sought much advice about ideas and specifics, coherence and cohesion, rhetorical moves and draft length, and they sought little advice about the use of language and the use of sources. The thematic analysis of CLs may also give a better indication of the type and content of peer feedback that PhD students expect and need. Understanding what students write about in their CLs could help inform the design of future rubrics for use within similar peer feedback processes. Thirdly, authors use much social presence in their CLs (e.g. 'Dear Bob,') and social presence may help writing groups develop a deeper sense of community. Fourthly, CLs may promote reflective writing practices. The study further suggests that a group's sense of community can be gauged from how the authors use certain indicators of 'Social Presence' (e.g. openings and closures). Furthermore, it was found that the participants who received explicit $C L$ instruction wrote longer and more informative CLs as compared to those who received minimal $\mathrm{CL}$ instruction. Thus, this study supports the principled use of CLs as a means of generating useful feedback comments and reflective practices in the context of doctorate writing groups. In addition, the results of this study further 
suggest that CLs could also be a useful pedagogical tool to promote writing skills at lower levels of study (e.g. at school and undergraduate levels).

Overall, the study suggests there are many affordances in using CLs in tandem with, or instead of, a rubric. As opposed to rubrics, CLs allow the authors to take multiple writing perspectives by providing background details about the draft, the intended audience, and the author. They allow authors to ask for specific help on perceived textual weaknesses through the derivation of their own assessment criteria and they can promote the use of social presence to develop a sense of a writing group community.

In other words, and in the context of doctorate writing groups, CLs are likely to generate reviewer feedback comments that exhibit desirable feedback traits conforming to the authors' expectations (Yallop, Taremaa and Leijen in press). These include feedback comments that are text-specific (Ferris 1997), global (Liu and Sadler 2003), justified (Leijen 2017), elicit multiple reviewer perspectives on the same textual aspect (Cho, Schunn and Wilson 2006), and are a response to the author's CL (Yallop and Leijen 2018). There is also broad evidence that CLs contain much social presence (e.g. 'Author Mitigation') and this affective theme cannot easily be communicated within rubrics. If a high, but not too high, amount of social presence is a predictor for a well-functioning writing group (Cahusac de Caux et al. 2017, Garrison, Anderson and Archer 1999, Shea et al., 2010), then CLs also serve an important affective purpose.

The process of writing CLs also seems to offer many cognitive affordances to authors. CLs may encourage authors to reflect upon their writing and writing practices that can be of benefit to writers at all levels of proficiency. One example is that the process of composing CLs could help authors take an audience perspective to writing and this process could help novice and intermediate writers progress from knowledge-telling to knowledge-transforming to knowledgecrafting (Kellogg, 2008). Although further quantitative and qualitative studies examining the usefulness of CLs to writers at lower-levels are needed, CLs could also be a useful pedagogical tool for writers at school and undergraduate levels. In addition, this study further shows that writing useful CLs in a PhD context can be explicitly taught. What constitutes a useful CL at a lower level of studies has not been the focus of this study and would be an interesting area for future research.

Thus, this study supports the principled use of CLs as an instructional tool within the feedback process for two main reasons. Firstly, CLs can help promote author reflective practices. Secondly, CLs can help reviewers generate useful written feedback comments. 


\section{References}

Aitchison, C. (2009). Writing groups for doctoral education. Studies in Higher Education, 34(8), 905-916. https://doi.org/10.1080/03075070902785580

Bazerman, C. (1988). Shaping written knowledge: The genre and activity of. Communication in linguistics. Madison: University of Wisconsin P.

Beldarrain, Y. (2006). Distance Education Trends: Integrating new technologies to foster student interaction and collaboration. Distance Education, 27(2), 139-153. https://doi.org/10.1080/01587910600789498

Bizup, J. (2008). BEAM: A Rhetorical Vocabulary for Teaching Research-Based Writing. Rhetoric Review, 27(1), 72-86. https://doi.org/10.1080/07350190701738858

Braun, V., and Clarke, V. (2006). Using thematic analysis in psychology. Qualitative Research in Psychology, 3(2), 77-101. https://doi.org/10.1191/1478088706qp063oa

Cahusac de Caux, B. K. C. D., Lam, C. K. C., Lau, R., Hoang, C. H., and Pretorius, L. (2017). Reflection for learning in doctoral training: writing groups, academic writing proficiency and reflective practice. Reflective Practice, 18(4), 463-473. https://doi.org/10.1080/14623943.2017.1307725

Cho, K., Schunn, C. D., and Charney, D. (2006). Commenting on writing: Typology and perceived helpfulness of comments from novice peer reviewers and subject matter experts. Written communication, 23(3), 260-294. https://doi.org/10.1177/0741088306289261

Cho, K., Schunn, C. D., and Wilson, R. W. (2006). Validity and reliability of scaffolded peer assessment of writing from instructor and student perspectives. Journal of Educational Psychology, 98(4), 891-901. https://doi.org/10.1037/0022-0663.98.4.891

Cotos, E., Link, S., and Huffman, S. (2016). Studying disciplinary corpora to teach the craft of discussion. Writing and Pedagogy, 87(1), 33-64. https://doi.org/10.1558/wap.v8il.27661

Daniel, F., Gaze, C. M., and Braasch, J. L. G. (2015). Writing Cover Letters That Address Instructor Feedback Improves Final Papers in a Research Methods Course. Teaching of Psychology, 42(1), 64-68. https://doi.org/10.1177/0098628314562680

Fahy, P. J. (2001). Addressing some Common Problems in Transcript Analysis. The International Review of Research in Open and Distributed Learning, 1(2). https://doi.org/10.19173/irrodl.v1i2.321

Ferris, D. R. (1997). The Influence of Teacher Commentary on Student Revision. TESOL Quarterly, 31(2), 315-339. https://doi.org/10.2307/3588049

Gao, Y., Schunn, C. D. D., and Yu, Q. (2019). The alignment of written peer feedback with draft problems and its impact on revision in peer assessment. Assessment and Evaluation in Higher Education, 44(2), 294-308. https://doi.org/10.1080/02602938.2018.1499075

Garrison, R. D., Anderson, T., and Archer, W. (1999). Critical Inquiry in a Text-Based Environment: Computer Conferencing in Higher Education. The Internet and Higher Education, 2(2), 87-105. https://doi.org/10.1016/S1096-7516(00)00016-6

Garrison, R. D., Anderson, T., and Archer, W. (2010). The first decade of the community of inquiry framework: A retrospective. The Internet and Higher Education, 13(1), 5-9. https://doi.org/10.1016/j.iheduc.2009.10.003 
Garrison, R. D, Cleveland-Innes, M., and Fung, T. S. (2010). Exploring causal relationships among teaching, cognitive and social presence: Student perceptions of the community of inquiry framework. The Internet and Higher Education, 13(1-2), 31-36. https://doi.org/10.1016/j.iheduc.2009.10.002

Gee, T. C. (1972). Students' Responses to Teacher Comments. Research in the Teaching of English, 6(2), 212-221. Retrieved from JSTOR.

Henri, F. (1992). Computer Conferencing and Content Analysis. In A. R. Kaye (Ed.), Collaborative Learning Through Computer Conferencing (pp. 117-136). Springer Berlin Heidelberg. * https://doi.org/10.1007/978-3-642-77684-7_8

Kellogg, R. T. (2008). Training writing skills: A cognitive developmental perspective. Journal of Writing Research, 1(1), 1-26. https://doi.org/10.17239/jowr-2008.01.01.1

Lam, C. K. C., Hoang, C. H., Lau, R. W. K., Cahusac de Caux, B., Chen, Y., Tan, Q. Q., and Pretorius, L. (2019). Experiential learning in doctoral training programmes: fostering personal epistemology through collaboration. Studies in Continuing Education, 41(1), 111-128. https://doi.org/10.1080/0158037X.2018.1482863

Leijen, D. A. (2017). A novel approach to examine the impact of web-based peer review on the revisions of L2 writers. Computers and Composition, 43, 35-54. https://doi.org/10.1016/i.compcom.2016.11.005

Leijen, D. A., and Leontjeva, A. (2012). Linguistic and review features of peer feedback and their effect on the implementation of changes in academic writing: A corpus based investigation. Journal of Writing Research, 4(2). https://doi.org/10.17239/ jowr$\underline{2012.04 .02 .4}$

Li, J., and Lindsey, P. (2015). Understanding variations between student and teacher application of rubrics. Assessing Writing, 26, 67-79. https://doi.org/10.1016/i.asw.2015.07.003

Lin, L., and Evans, S. (2012). Structural patterns in empirical research articles: A crossdisciplinary study. English for Specific Purposes, 31(3), 150-160.

https://doi.org/10.1016/j.esp.2011.10.002

Liu, J., and Sadler, R. W. (2003). The effect and affect of peer review in electronic versus traditional modes on L2 writing. Journal of English for Academic Purposes, 2(3), 193227. https://doi.org/10.1016/S1475-1585(03)00025-0

Lundstrom, K., and Baker, W. (2009). To give is better than to receive: The benefits of peer review to the reviewer's own writing. Journal of Second Language Writing, 18(1), 3043. https://doi.org/10.1016/j.jslw.2008.06.002

Maher, D., Seaton, L., McMullen, C., Fitzgerald, T., Otsuji, E., and Lee, A. (2008). 'Becoming and being writers': the experiences of doctoral students in writing groups. Studies in Continuing Education, 30(3), 263-275. https://doi.org/10.1080/01580370802439870

Mikkelsen, J. B. (2010). Writing Groups: Why and How? (pp. 1-35). Teaching and Learning Unit of Social Sciences - The University of Copenhagen.

Moxley, J. (2013). Big data, learning analytics, and social assessment. The Journal of Writing Assessment, 6(1), 1-10.

Murray, R., and Moore, S. (2006). The Handbook of Academic Writing: A Fresh Approach. McGraw-Hill Education (UK).

Nicol, D., Thomson, A., and Breslin, C. (2014). Rethinking feedback practices in higher education: A peer review perspective. Assessment and Evaluation in Higher Education, 39(1), 102-122. https://doi.org/10.1080/02602938.2013.795518 
Pyhältö, K., Peltonen, J., Castelló, M., and McAlpine, L. (2019). What sustains doctoral students' interest? Comparison of Finnish, UK and Spanish doctoral students' perceptions. Compare: A Journal of Comparative and International Education, $0(0)$, 1-16. https://doi.org/10.1080/03057925.2019.1585229

Rollinson, P. (2004). Experiences and perceptions in an ESL academic writing peer response group. Estudios ingleses de la Universidad Complutense, (12), 79-108.

Rourke, L., Anderson, T., Garrison R. D., and Archer, W. (n.d.). Assessing Social Presence in Asynchronous Text-based Computer Conferencing. 18.

Ruiying, Y., and Allison, D. (2003). Research articles in applied linguistics: moving from results to conclusions. English for Specific Purposes, 22(4), 365-385. https://doi.org/10.1016/S0889-4906(02)00026-1

Salager-Meyer, F. (1994). Hedges and Textual Communicative Function in Medical English Written Discourse. English for Specific Purposes, 13(2), 149-170. https://doi.org/10.1016/0889-4906(94)90013-2

Shea, P., Hayes, S., Vickers, J., Gozza-Cohen, M., Uzuner, S., Mehta, R., Rangan, P. (2010). A re-examination of the community of inquiry framework: Social network and content analysis. The Internet and Higher Education, 13(1-2), 10-21. https://doi.org/10.1016/i.iheduc.2009.11.002

Short, J. ,Williams, E. and Christie, B. (1976). The social psychology of telecommunications. Toronto: John Wiley and Sons.

Strauss, A., and Corbin, J. M. (1997). Grounded Theory in Practice. SAGE.

Swales, J. (1990). Genre Analysis: English in Academic and Research Settings. Cambridge University Press.

Thurston, A. (2005). Building online learning communities. Technology, Pedagogy and Education, 14(3), 353-369. https://doi.org/10.1080/14759390500200211

White, C. (2005). Contribution of Distance Education to the Development of Individual Learners. Distance Education, 26(2), 165-181. https://doi.org/10.1080/01587910500168835

Yallop, R. M. A. (2016). Measuring affective language in known peer feedback on L2 Academic writing courses: A novel approach. Eesti Rakenduslingvistika Ühingu Aastaraamat, 12(0), 287-308. https://doi.org/10.5128/ERYa12.17

Yallop, R. M. A. (2017). Investigating 'mitigation' and 'praise' as affective factors influencing the implementation of peer feedback within an asynchronous text environment. Unterstützung von L2-Schreibkompetenzen an deutschen Universitäten: Englisch und Deutsch als Fremd- und Zweitsprache. 152.

Yallop, R. M. A., and Leijen, D. A. J. (2018). The perceived effectiveness of written peer feedback comments within L2 English academic writing courses. Eesti Rakenduslingvistika Ühing Aastaraamat, 14(0), 247-271. https://doi.org/10.5128/ERYa14.15

Yallop, R. M. A., Taremaa, P. and Leijen, D. A. J (in press). The affect and effect of asynchronous written feedback comments on the peer feedback process: an ethnographic case-study approach within one L2 English doctorate writing group. Journal of Writing Research, $x x(\mathrm{xx}), \mathrm{p} . \mathrm{xx}-\mathrm{xx}$ 


\section{Appendix A. Writing assessment rubric from MyReviewers}

\begin{tabular}{|c|c|c|c|c|}
\hline Criteria & Level & $\begin{array}{c}\text { Emerging } \\
0\end{array}$ & Developing & $\begin{array}{c}\text { Mastering } \\
4\end{array}$ \\
\hline \multirow[t]{2}{*}{ Focus } & Basics & $\begin{array}{l}\text { Does not meet assignment } \\
\text { requirements }\end{array}$ & $\begin{array}{l}\text { Partially meets assignment } \\
\text { requirements }\end{array}$ & $\begin{array}{l}\text { Meets assignment } \\
\text { requirements }\end{array}$ \\
\hline & Critical Thinking & $\begin{array}{l}\text { Absent or weak thesis; } \\
\text { ideas are underdeveloped, } \\
\text { vague or unrelated to } \\
\text { thesis; poor analysis of } \\
\text { ideas relevant to thesis }\end{array}$ & $\begin{array}{l}\text { Predictable or unoriginal } \\
\text { thesis; ideas are partially de-- } \\
\text { veloped and related to thesis; } \\
\text { inconsistent analysis of subject } \\
\text { relevant to thesis }\end{array}$ & $\begin{array}{l}\text { Insightful/intriguing thesis; } \\
\text { ideas are convincing and } \\
\text { compelling; cogent analysis } \\
\text { of subject relevant to thesis }\end{array}$ \\
\hline Evidence & Critical Thinking & $\begin{array}{l}\text { Sources and supporting } \\
\text { details lack credibility; } \\
\text { poor synthesis of primary } \\
\text { and secondary } \\
\text { sources/evidence relevant } \\
\text { to thesis; poor synthesis of } \\
\text { visuals/personal } \\
\text { experience/anecdotes rel- } \\
\text { evant to thesis; rarely dis- } \\
\text { tinguishes between } \\
\text { writer's ideas and source's } \\
\text { ideas }\end{array}$ & $\begin{array}{l}\text { Fair selection of credible } \\
\text { sources and supporting de- } \\
\text { tails; unclear relationship be- } \\
\text { tween thesis and primary and } \\
\text { secondary sources/evidence; } \\
\text { ineffective synthesis of } \\
\text { sources/evidence relevant to } \\
\text { thesis; occasionally effective } \\
\text { synthesis of visuals/personal } \\
\text { experience/anecdotes relevant } \\
\text { to thesis; inconsistently distin- } \\
\text { guishes between writer's ideas } \\
\text { and source's ideas }\end{array}$ & $\begin{array}{l}\text { Credible and useful sources } \\
\text { and supporting details; } \\
\text { cogent synthesis of primary } \\
\text { and secondary } \\
\text { sources/evidence relevant } \\
\text { to thesis; clever synthesis of } \\
\text { visuals/personal } \\
\text { experience/anecdotes rel- } \\
\text { evant to thesis; distin- } \\
\text { guishes between writer's } \\
\text { ideas and source's ideas }\end{array}$ \\
\hline \multirow[t]{2}{*}{$\begin{array}{l}\text { Organiza- } \\
\text { tion }\end{array}$} & Basics & $\begin{array}{l}\text { Confusing opening; } \\
\text { absent, inconsistent, or } \\
\text { non-relevant topic sen- } \\
\text { tences; few transitions and } \\
\text { absent or unsatisfying con- } \\
\text { clusion }\end{array}$ & $\begin{array}{l}\text { Uninteresting or somewhat } \\
\text { trite introduction, inconsistent } \\
\text { use of topics sentences, } \\
\text { segues, transitions, and me- } \\
\text { diocre conclusion }\end{array}$ & $\begin{array}{l}\text { Engaging introduction, rel- } \\
\text { evant topic sentences, good } \\
\text { segues, appropriate transi- } \\
\text { tions, and compelling con- } \\
\text { clusion }\end{array}$ \\
\hline & Critical Thinking & $\begin{array}{l}\text { Illogical progression of } \\
\text { supporting points; lacks } \\
\text { cohesiveness }\end{array}$ & $\begin{array}{l}\text { Supporting points follow some- } \\
\text { what logical progression; occa- } \\
\text { sional wandering of ideas; some } \\
\text { interruption of cohesiveness }\end{array}$ & $\begin{array}{l}\text { Logical progression of sup- } \\
\text { porting points; very cohe- } \\
\text { sive }\end{array}$ \\
\hline \multirow{2}{*}{ 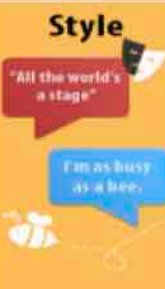 } & Basics & $\begin{array}{l}\text { Frequent grammar, punc- } \\
\text { tuation errors; inconsistent } \\
\text { point of view }\end{array}$ & $\begin{array}{l}\text { Some grammar/punctuation } \\
\text { errors occur in some places; } \\
\text { somewhat consistent point of } \\
\text { view }\end{array}$ & $\begin{array}{l}\text { Correct grammar and punc- } \\
\text { tuation; consistent point of } \\
\text { view }\end{array}$ \\
\hline & Critical Thinking & $\begin{array}{l}\text { Significant problems with } \\
\text { syntax, diction, word } \\
\text { choice, and vocabulary }\end{array}$ & $\begin{array}{l}\text { Occasional problems with } \\
\text { syntax, diction, word choice, } \\
\text { and vocabulary }\end{array}$ & $\begin{array}{l}\text { Rhetorically-sound syntax, } \\
\text { diction, word choice, and } \\
\text { vocabulary; effective use of } \\
\text { figurative language }\end{array}$ \\
\hline$\sqrt{\frac{1}{2}}$ & Basics & $\begin{array}{l}\text { Little compliance with ac- } \\
\text { cepted documentation style } \\
\text { (i.e., MLA, APA) for paper } \\
\text { formatting, in-text cita- } \\
\text { tions, annotated bibliogra- } \\
\text { phies, and works cited; } \\
\text { minimal attention to docu- } \\
\text { ment design }\end{array}$ & $\begin{array}{l}\text { Inconsistent compliance with } \\
\text { accepted documentation style } \\
\text { (i.e., MLA, APA) for paper for- } \\
\text { matting, in-text citations, an- } \\
\text { notated bibliographies, and } \\
\text { works cited; some attention to } \\
\text { document design }\end{array}$ & $\begin{array}{l}\text { Consistent compliance with } \\
\text { accepted documentation } \\
\text { style (i.e., MLA, APA) for } \\
\text { paper formatting, in-text } \\
\text { citations, annotated bibli- } \\
\text { ographies, and works cited; } \\
\text { strong attention to docu- } \\
\text { ment design }\end{array}$ \\
\hline
\end{tabular}

Source: Moxley, J. (2013). 'Big data, learning analytics, and social assessment'. The Journal of Writing Assessment 6 (1): 4 


\title{
Appendix B. Online writing support for writing CLs (Course2019)
}

\section{How to write a good cover letter}

\begin{abstract}
What is a cover letter?
Your cover letter should be added as a separate text to the beginning of the draft you are submitting to your colleagues for review. The cover letter is the method by how you communicate to your colleagues about how they should assess your draft. It should include all the information that the reviewers need to know in order to give you useful and critical feedback. This includes background information about your draft article and any specific areas that you wish to seek advice on. There is no set format for this, so you are free to write your cover letter as you think is best.
\end{abstract}

Why should I write a cover letter?

It is very important that you write a clear and concise cover letter so that your writing group members know exactly how to assess your text. This is because without a cover letter, the reviewers can only guess what feedback you require. Another advantage of writing a cover letter is that authors often find this helps them to identify weaknesses in their own current draft. It is for these reasons that we strongly encourage you to take time and consideration in composing a cover letter.

How do I write a good cover letter?

A good cover letter generally contains some or all of the following information:

1. Background information about the text.

"What I submit below is the first draft of the introduction of a paper ..."

2. Clear guidelines on what aspects of the text feedback is expected on (this can include both positive and negative features). "Have I clearly identified the research gap in my introduction?"

"Can you understand the gist of what I have written?"

"Please also highlight any aspects of my draft that are convincing and easy to read."

3. An invitation to comment on (or not comment on) other issues not included in the cover letter "Please do comment on any other parts of the text you do not understand."

"Please don't comment on local issues (e.g., spelling and grammar) unless they impede understanding."

4. In-text comment boxes on specific points within your draft that specific help is needed with.

5. Other information (not specified above) that is relevant that will help the reviewers give useful and critical feedback.

Furthermore, we would recommend that you write your cover letter in a polite and friendly way. You can use openings (e.g. "Dear Writing Group"), closings (e.g. "All the best, $A n u^{\prime \prime)}$, and other friendly language such as reference to past feedback (e.g. "Thank you for your comments from last week.") and to future contact (e.g "I look forward to our next meeting.").

In addition do take a realistic and reviewer's perspective. If your writing group members are not experts in your field, do not expect them to comment on specific and specialised concepts included in your draft as your supervisor (should) do. However, your colleagues will be educated readers with at least some knowledge about your area of expertise. Thus, they can most definitely be trusted to comment on passages of your text that seem 'illogical' or difficult to read.

Finally, do remember that your cover letter is the very place to underline the doubts, issues and problems that you might have with your current draft (and not to hide them as we usually do with the final product).

\footnotetext{
Take a reviewer's perspective

Consider that you are going to give feedback on your own draft(s) based solely on your cover letter. Look back through the cover letter you are writing (or have written) and consider the following points:

1. Do your cover letters include all or some of the points mentioned above?

2. If you were the reviewer, would you know exactly how to give useful feedback on your draft.

3. Have you received useful and/or expected feedback on your draft based on your cover letter?

4. If not, how could you improve your cover letter(s)?

Please remember to include your cover letter on the same document (and before) your draft for submission.

Please remember to include your cover letter on the same document (and before) your draft for submission.
} 